\title{
Spectral surface albedo over Morocco and its impact on radiative forcing of Saharan dust
}

\author{
By EIKE BIERW IRTH ${ }^{1,6,7 *}$, M ANFRED WENDISCH ${ }^{1,6}$, ANDRÉ EHRLICH ${ }^{1,6}$, BIRGIT \\ HEESE $^{1,2}$, MATTHIAS TESCHE ${ }^{1}$, DIETRICH ALTHAUSEN ${ }^{1}$, ALEXANDER SCHLADITZ ${ }^{1}$, \\ DETLEF MÜLLER ${ }^{1}$, SEBASTIAN OTTO ${ }^{3}$, THOMAS TRAUTMANN ${ }^{3}$, TILMAN DINTER ${ }^{4}$, \\ W OLFGANG VON HOYNINGEN-HUENE ${ }^{4}$ and R ALPH KA HN ${ }^{5} \ddagger, \quad{ }^{1}$ Leibniz Institute for Tropospheric \\ Research, Permoserstraße 15, 04318 Leipzig, Germany; ${ }^{2}$ Meteorological Institute, University of Munich, \\ Theresienstraße 37, 80333 München, Germany; ${ }^{3}$ Remote Sensing Technology Institute IMF, German Aerospace Center \\ (DLR), Münchner Straße 20, 82234 Oberpfaffenhofen, Germany; ${ }^{4}$ Institute of Environmental Physics, University of \\ Bremen, Otto-Hahn-Allee 1, 28359 Bremen, Germany; ${ }^{5}$ Jet Propulsion Laboratory (JPL), 4800 Oak Grove Dr., \\ Pasadena, CA 91109, USA; ${ }^{6}$ Institute for Atmospheric Physics, Johannes Gutenberg University Mainz, Becherweg 21, \\ 55099 Mainz, Germany; ${ }^{7}$ Laboratory for Atmospheric and Space Physics, University of Colorado, Boulder, CO \\ 80309, USA
}

(Manuscript received 21 December 2007, in final form 15 September 2008)

\begin{abstract}
In May-June 2006, airborne and ground-based solar $(0.3-2.2 \mu \mathrm{m})$ and thermal infrared $(4-42 \mu \mathrm{m})$ radiation measurements have been performed in Morocco within the Saharan Mineral Dust Experiment (SAMUM). Upwelling and downwelling solar irradiances have been measured using the Spectral Modular Airborne Radiation Measurement System (SMART)-Albedometer. With these data, the areal spectral surface albedo for typical surface types in southeastern Morocco was derived from airborne measurements for the first time. The results are compared to the surface albedo retrieved from collocated satellite measurements, and partly considerable deviations are observed. Using measured surface and atmospheric properties, the spectral and broad-band dust radiative forcing at top-of-atmosphere (TOA) and at the surface has been estimated. The impact of the surface albedo on the solar radiative forcing of Saharan dust is quantified. In the SAMUM case of 19 May 2006, TOA solar radiative forcing varies by $12 \mathrm{~W} \mathrm{~m}^{-2}$ per 0.1 surface-albedo change. For the thermal infrared component, values of up to $+22 \mathrm{~W} \mathrm{~m}^{-2}$ were derived. The net (solar plus thermal infrared) TOA radiative forcing varies between -19 and $+24 \mathrm{~W} \mathrm{~m}^{-2}$ for a broad-band solar surface albedo of 0.0 and 0.32 , respectively. Over the bright surface of southeastern Morocco, the Saharan dust always has a net warming effect.
\end{abstract}

\section{Introduction}

One of the goals of the Saharan Mineral Dust Experiment (SAMUM) is the quantification of the effects of the Saharan dust plume on the solar (or short wave; $0.3-4 \mu \mathrm{m}$ ) and thermal infrared (or long wave; 4-50 $\mu \mathrm{m}$ ) radiation field (Heintzenberg, 2008). For an assessment of the radiative effect of Saharan dust it is crucial to have accurate data about the optical properties of the dust, and about the spectral surface albedo in the region of interest. Literature values about the dust optical properties vary widely and hence cannot be applied simply for an actual dust situation (see, e.g. Sokolik and Toon, 1996). Also representative

\footnotetext{
*Corresponding author.

e-mail: Eike.Bierwirth@gmx.de

${ }^{\ddagger}$ Now at: NASA Goddard Space Flight Center, Greenbelt, MD 20771, USA.

DOI: $10.1111 / \mathrm{j} .1600-0889.2008 .00395 . \mathrm{x}$
}

data about the surface albedo of the hamada desert in Morocco and about its variability have so far not been available from in situ measurements. Saharan Mineral Dust Experiment offers a unique opportunity for studies of the radiative effect of Saharan dust, because it includes measurements of the optical and microphysical properties of Saharan dust as well as measurements of the spectral surface albedo and its variability. In this paper, airborne and ground-based radiation measurements (spectral solar and broad-band thermal infrared) are combined with radiative transfer calculations that use the measured optical properties of Saharan dust to quantify its radiative impact close to the dust source, that is, over southeastern Morocco. In particular, the influence of the spectral surface albedo and its variations on the dust radiative forcing is evaluated. A related paper of this special issue is concerned with dust radiative properties on the basis of microphysical measurements considering non-sphericity effects of the dust particles (Otto et al., 2008). 


\subsection{Definitions}

We have measured irradiances $F$ as well as actinic flux densities $F^{\mathrm{a}}$ from an airborne platform and at the surface. Upwelling and downwelling irradiances are marked by an upward $\left(F^{\uparrow}\right)$ and downward $\left(F^{\downarrow}\right)$ arrow, respectively. Spectral quantities are marked with subscript $\lambda$. The albedo $\rho_{\lambda}$ at altitude $z$ is defined as the ratio of upwelling and downwelling irradiances:

$\rho_{\lambda}(z)=\frac{F_{\lambda}^{\uparrow}(z)}{F_{\lambda}^{\downarrow}(z)}$

with $\rho_{\lambda}(0)$ called the 'surface albedo'. Radiative forcing is defined as the difference between the net irradiances of a perturbed (subscript 'pert') and a non-perturbed (subscript ' 0 ') situation:

$\Delta F=\left(F^{\downarrow}-F^{\uparrow}\right)_{\text {pert }}-\left(F^{\downarrow}-F^{\uparrow}\right)_{0}$.

According to this definition, a positive $\Delta F$ at top-of-atmosphere (TOA) corresponds to a warming of the Earth-atmosphere system by the perturbation, either by an increase of incoming radiation $F^{\downarrow}$ (TOA; like in the case of enhanced solar activity) or by a reduction of outgoing radiation $F^{\uparrow}$ (TOA; like in the case of a greenhouse effect). Due to different physical mechanisms, the radiative forcing is usually discussed separately for the solar spectral range $(0.3-4 \mu \mathrm{m})$ and for the thermal infrared spectral range $(4-50 \mu \mathrm{m})$. The 'net' radiative forcing is the sum of the solar and the thermal infrared component.

\subsection{Available surface-albedo data}

Not many cases of airborne measurements of the spectral surface albedo are reported, for example, by Webb et al. (2000), Rutan et al. (2003), Webb et al. (2004), Wendisch et al. (2004) and Coddington et al. (2008); also of the broad-band surface albedo (e.g. by Rockwood and Cox, 1978; Matthews et al., 2002). Ground-based measurements of the spectral surface albedo are more common (e.g. Grenfell et al., 1994; Feister and Grewe, 1995; Kylling et al., 2000; Aoki et al., 2002; Wuttke et al., 2006). Comparison studies between space-borne, airborne and ground-based albedo measurements are presented, for example, by Michalsky et al. (2003) and Trishchenko et al. (2004). The impact of surface-albedo inhomogeneities is investigated in 1-D and 3-D models by Ricchiazzi and Gautier (1998) and by McComiskey et al. (2006). Surface-albedo data derived from space-borne platforms are available from the Moderate Resolution Imaging Spectro-radiometer (MODIS) seven wavelength bands 0.47-2.1 $\mu \mathrm{m}$, (Schaaf et al., 2002), from the Medium Resolution Imaging Spectrometer (MERIS; 15 bands 412-900 nm) and from the Multiangle Imaging Spectroradiometer (MISR; four wavelengths $446-866 \mathrm{~nm}$ at nine viewing angles; see Diner et al., 1998). Measurements of the Advanced Very High Resolution Radiometer (AVHRR) are used to derive the broad-band surface albedo by an empirical linear function (Song and Gao, 1999).

\subsection{Radiative forcing in literature}

An overview of dust-forcing values at TOA and the surface in recent publications is given in Table 1 .

Hansen et al. (1997) state that the radiative forcing of aerosol at the surface shifts from cooling to heating if the singlescattering albedo of the aerosol particles exceeds 0.86 , but also that the sign of the forcing still depends on other parameters, such as the altitude of the aerosol layer. Wang et al. (2006) performed model studies of the radiative forcing of an Asian dust plume with respect to the aerosol optical depth (AOD), the single-scattering albedo and the asymmetry parameter. If the single-scattering albedo of the dust is increased from 0.80 to 0.86 , they find that the TOA net radiative forcing over bright desert surfaces drops from +12 to $+3 \mathrm{~W} \mathrm{~m}^{-2}$, while the surface forcing shifts from below $-80 \mathrm{~W} \mathrm{~m}^{-2}$ to values between -70 and $-80 \mathrm{~W} \mathrm{~m}^{-2}$. Over darker surfaces, however, the TOA net forcing is always negative (cooling). Shell and Somerville (2007b) found that the net radiative forcing of dust at TOA increases (i.e. a stronger tendency to warming) with an increase of the asymmetry parameter or the dust-particle size (which is related to each other), and with a decrease of the dust singlescattering albedo. Furthermore, they state that it tends to be more positive if the dust layer is elevated higher in the atmosphere. They confirm the radiative forcing at the surface to be generally negative and larger in magnitude than the TOA forcing. Tegen and Lacis (1996) relate dust forcing at the tropopause to particle size and dust-layer height. The forcing is negative for particles smaller than a critical size which depends on the dust-layer height, and positive for larger particles. Forcing is smaller for lower dust layers.

Diaz et al. (2001) modelled the local solar radiative forcing of mineral dust over land at $-4.5 \mathrm{~W} \mathrm{~m}^{-2}$ with an assumed land surface albedo of 0.22 and averaged over a distribution of AOD values between 0.06 and 0.6. The formula of Sokolik and Toon (1996) suggests that the radiative forcing by dust over land may vary between +5 and $-24 \mathrm{~W} \mathrm{~m}^{-2}$ depending on the aerosol model (with cloud fraction set to zero and AOD set to 0.321 as measured at $1 \mu \mathrm{m}$ on 19 May).

Balkanski et al. (2007) found that the solar radiative forcing of dust is positive if the (broadband) surface albedo exceeds 0.2 . Aerosol radiative forcing studies (not only dust) by Liu et al. (2007) find positive TOA values only over Central Asia and the Arctic and link this to the bright surface albedo of those regions. Nair et al. (2007) investigated the solar forcing of a surface-albedo change and obtained a value of $-14 \mathrm{~W} \mathrm{~m}^{-2}$ for a change from native vegetation to cropland in Western Australia. Stone et al. (2007) investigate an Asian dust event in Alaska over snow-covered surfaces. They found that a variation of $1 \%$ in the surface-albedo input to the model leads to a variation of $5 \%$ in the solar forcing at the surface. Lyamani et al. (2006) obtained solar forcings of a dust event in Spain between -2 
Table 1. Values of dust radiative forcing from literature for solar (short wave, SW), thermal infrared (long wave, $\mathrm{LW}$ ) and net (SW+LW) forcing at top-of-atmosphere (TOA) and at the surface, in $\mathrm{W} \mathrm{m}^{-2}$

\begin{tabular}{|c|c|c|c|c|c|c|c|}
\hline Authors & $\begin{array}{l}\text { TOA } \\
\text { SW }\end{array}$ & $\begin{array}{l}\text { TOA } \\
\text { LW }\end{array}$ & $\begin{array}{c}\text { TOA } \\
\text { net }\end{array}$ & $\begin{array}{l}\text { Surface } \\
\text { SW }\end{array}$ & $\begin{array}{l}\text { Surface } \\
\text { LW }\end{array}$ & $\begin{array}{c}\text { Surface } \\
\text { net }\end{array}$ & Remarks \\
\hline \multicolumn{8}{|c|}{ Annual and global mean } \\
\hline Tegen et al. (1996) & & & 0.14 & & & & \\
\hline \multirow[t]{2}{*}{ Miller and Tegen (1998) } & & & -0.1 & & & -2.1 & Soil dust annually \\
\hline & -0.45 & 0.46 & 0.0 & -2.96 & 0.24 & -2.72 & Soil dust, summer \\
\hline Woodward (2001) & -0.16 & 0.23 & 0.07 & -1.22 & 0.40 & -0.82 & \\
\hline \multirow[t]{2}{*}{ Myhre and Stordal (2001) } & -0.02 & 0.41 & 0.39 & & & & Dust type 1 \\
\hline & -0.53 & 0.13 & -0.40 & & & & Dust type 2 \\
\hline Jacobson (2001) & & & -0.14 & & & -0.85 & \\
\hline Perlwitz et al. (2001) & -0.5 & 0.1 & -0.4 & -2.1 & 0.4 & -1.7 & \\
\hline Claquin et al. (2003) & & & -1.2 & & & & \\
\hline Myhre et al. (2003) & & & -0.4 & & & & Saharan dust \\
\hline Miller et al. (2004) & -0.33 & 0.15 & -0.18 & -1.82 & 0.18 & -1.64 & \\
\hline Miller et al. (2006) & & & -0.39 & & & -0.82 & \\
\hline Yoshioka et al. (2007) & -0.92 & 0.31 & -0.60 & -1.59 & 1.13 & -0.46 & \\
\hline Shell and Somerville (2007a) & -0.73 & 0.23 & -0.49 & -1.34 & 0.37 & -0.97 & \\
\hline \multirow[t]{2}{*}{ Balkanski et al. (2007) } & -0.68 & 0.29 & -0.39 & & & -0.92 & Dust type S1 \\
\hline & 0.05 & 0.30 & 0.35 & & & -1.44 & Dust type S2 \\
\hline \multicolumn{8}{|c|}{ Regional/local } \\
\hline Tegen and Lacis (1996) & +15 & +5 & & & & & Regional, annual mean \\
\hline Tegen et al. (1996) & & & & to +5.5 & & & Locally \\
\hline \multirow[t]{2}{*}{ Diaz et al. (2001) } & -9.7 & & & & & & Locally, over ocean \\
\hline & -4.5 & & & & & & Locally, over land \\
\hline Haywood et al. (2001) & $-(35-60)$ & 4.4 & & & & & $\begin{array}{l}\text { Locally, over ocean, } \\
\omega_{0}=0.86\end{array}$ \\
\hline Haywood et al. (2003) & $-(44-129)$ & & & & & & $\begin{array}{l}\text { Locally, over ocean, } \\
\qquad \omega_{0}=0.95\end{array}$ \\
\hline Highwood et al. (2003) & & 6.5 & & & 11.5 & & Locally, over ocean \\
\hline \multirow[t]{2}{*}{ Meloni et al. (2004) } & $-(5-6)$ & & & $-(12-14)$ & & & $\begin{array}{l}\text { Locally } 14 / 07 / 2002 \\
\omega_{0}=0.96-0.97\end{array}$ \\
\hline & $-(1-2)$ & & & $-(23-25)$ & & & $\begin{array}{c}\text { Locally } 16 / 07 / 2002 \\
\omega_{0}=0.88-0.89\end{array}$ \\
\hline Costa et al. (2006) & -40 & & & $<-400$ & & & $\begin{array}{l}\text { Yellow Sea, single event, } \\
\omega_{0}=0.76, \text { AOT }=0.4-2.0\end{array}$ \\
\hline \multirow[t]{2}{*}{ Deepshikha et al. (2006) } & +4.5 & & & -22.8 & & & $\begin{array}{l}\text { Regional and annual mean, } \\
\qquad \omega_{0}=0.82\end{array}$ \\
\hline & -0.9 & & & -11.8 & & & $\begin{array}{l}\text { Regional and annual mean, } \\
\qquad \omega_{0}=0.97\end{array}$ \\
\hline Wang et al. (2006) & -4.3 & 1.0 & -3.3 & -10.0 & 1.6 & -8.4 & $\begin{array}{c}\text { Regional mean, } \\
\omega_{0}=0.88-0.92\end{array}$ \\
\hline Shell and Somerville (2007b) & -0.65 & & -0.42 & -1.3 & & -0.88 & $\begin{array}{l}\text { Local instantaneous; broadband } \\
\qquad \omega_{0}=0.97\end{array}$ \\
\hline Christopher and Jones (2007) & -7.75 & 1.44 & -6.31 & & & & $\begin{array}{l}\text { Summer mean, } \\
\text { Atlantic Ocean }\end{array}$ \\
\hline \multirow[t]{3}{*}{ Zhu et al. (2007) } & -8.4 & 4.4 & -4.1 & -11.2 & 5.3 & -5.9 & $\begin{array}{c}\text { Spring mean, Yellow Sea, } \\
\qquad \omega_{0}=0.964\end{array}$ \\
\hline & -12.4 & 5.4 & -7.0 & -22.4 & 4.6 & -17.8 & $\begin{array}{l}\text { Summer mean, Arabian Sea, } \\
\qquad \omega_{0}=0.933\end{array}$ \\
\hline & -14.4 & 8.3 & -6.1 & -23.0 & 8.8 & -14.2 & $\begin{array}{c}\text { Summer mean, Saharan Coast, } \\
\qquad \omega_{0}=0.948\end{array}$ \\
\hline
\end{tabular}


Table 1. Continued.

\begin{tabular}{lccccccc}
\hline Authors & $\begin{array}{c}\text { TOA } \\
\text { SW }\end{array}$ & $\begin{array}{c}\text { TOA } \\
\text { LW }\end{array}$ & $\begin{array}{c}\text { TOA } \\
\text { net }\end{array}$ & $\begin{array}{c}\text { Surface } \\
\text { SW }\end{array}$ & $\begin{array}{c}\text { Surface } \\
\text { LW }\end{array}$ & $\begin{array}{c}\text { Surface } \\
\text { net }\end{array}$ & Remarks \\
\hline Helmert et al. (2007) & -178 & 32 & -146 & -291 & 77 & -214 & D1 REFL S Sahara \\
& -19 & 4 & -15 & -29 & 9 & -20 & D1 REFL N Sahara \\
& -15 & 2 & -13 & -15 & 3 & -12 & D1 REFL Europe \\
& -146 & 33 & -113 & -338 & 87 & -251 & D1 ABS S Sahara \\
& -17 & 5 & -12 & -34 & 10 & -24 & D1 ABS N Sahara \\
& -12 & 2 & -10 & -15 & 3 & -12 & D1 ABS Europe \\
Otto et al. (2007) & -61 & 8 & -53 & & & & Ocean, $\omega_{0}=0.78$ \\
& 97 & 10 & 107 & & & & Bright desert, $\omega_{0}=0.78$
\end{tabular}

Note: Balkanski dust type S1: 1.5\% hematite internally mixed; S2: Patterson-Volz refractive indices. Helmert et al. discuss D1 (dust event of 13 October 2001) for dust types REFL (more reflective) and ABS (more absorbing) with single-scattering albedo (for particles of $5 \mu \mathrm{m}$ effective radius) of 0.967 and 0.901 , respectively. $\omega_{0}$, if given, is at $500 \mathrm{~nm}$ or $550 \mathrm{~nm}$ unless otherwise stated.

and $-12 \mathrm{~W} \mathrm{~m}^{-2}$ in dependence on the solar zenith angle, with strongest forcing occurring at $70^{\circ}$.

\subsection{Scope and motivation}

In this paper, the impact of variations of the spectral surface albedo on the solar radiative forcing of Saharan dust is investigated. The combined experience of SAMUM participants in modelling and measuring radiation as well as the microphysical and optical properties of dust gives a unique opportunity for such a study. For the first time, the optical properties of a wellcharacterized Saharan dust plume close to its source are combined with airborne measurements of the areal spectral surface albedo of a desert area. Taking measurements from an airborne platform ensures that the measured data are representative for the region, and they yield information about the spatial variability of the surface albedo.

The surface albedo is a crucial input parameter for radiative transfer calculations, especially over land where surface-albedo values are larger and more variable than over oceans. In particular, most aerosol retrievals over land based on satellite measurements rely upon crude estimates of the surface reflection to distinguish between the strong contribution from surface reflection and the typically much smaller contribution of reflection caused by the aerosol particles to the satellite radiance signal measured at TOA. A wide range of methods and algorithms has been developed for this purpose, but intercomparisons reveal still unresolved discrepancies. Inconsistencies between several retrieval algorithms using data from various satellite instruments are shown in a study by Kokhanovsky et al. (2007): the different approaches to the surface-aerosol signal separation yield 'not always [...] consistent values of the aerosol properties', while the retrieval is further complicated by the need of a priori assumptions about the scattering phase function and the singlescattering albedo of the aerosol particles. In a comparison of single-view and dual-view techniques of the retrieval of AOD from satellite data, Thomas et al. (2007) find that the dual-view approach yields better results over land because it is less dependent on assumptions about the surface reflectance. But even with MISR's nine viewing angles, some assumptions are required to derive the combination of surface and atmospheric properties from TOA radiance measurements alone (Kahn et al., 2007; Martonchik et al., 2008). The spectral surface albedo which is presented in this work is applied in an ongoing sensitivity study for the MISR retrieval of aerosol properties.

Although a global in situ data set of the surface albedo is impossible to obtain and would have to take into account the temporal development of the surface properties as well, local measurements are helpful for estimating the uncertainty of a retrieval and its assumptions. This is especially true for the Sahara desert where (1) most of the global mineral-dust aerosol is produced, (2) the surface albedo is generally relatively high and (3) in situ measurements are scarce. Furthermore, in situ measurements of the desert surface albedo can be considered stable over relatively long periods, because the typical reasons for short-term changes, like rainfall and vegetation changes, are rare.

\section{Experiment}

\subsection{Airborne radiation measurements}

Measurement flights have been performed with a Partenavia P68B aircraft (call sign D-GERY) which was based at the airport of the southeastern Moroccan city of Ouarzazate. Solar spectral irradiances have been measured by the Spectral Modular Airborne Radiation Measurement System (SMART)Albedometer, developed at the Leibniz Institute for Tropospheric Research (IfT), Leipzig (Germany). Measurements with earlier versions of this instrument are described by Wendisch et al. 
Table 2. Technical description of the spectrometers that have been used in the SMART-Albedometer and in CORAS during the SAMUM experiment. Arrows indicate for each quantity whether its upwelling $(\uparrow)$ and/or downwelling $(\downarrow)$ component has been measured

\begin{tabular}{lccccc}
\hline Name & Type & $\begin{array}{c}\text { Spectral } \\
\text { range }(\mathrm{nm})\end{array}$ & $\begin{array}{c}\text { Number } \\
\text { of pixels }\end{array}$ & $\begin{array}{c}\text { Resolution } \\
\text { FWHM (nm) }\end{array}$ & $\begin{array}{c}\text { Measured } \\
\text { quantity }\end{array}$ \\
\hline VIS & MCS 55 UV/VIS & $290-1000$ & 1024 & $2-3$ & $\begin{array}{c}\text { Irradiance }(\uparrow \downarrow) \\
\text { Irradiance }(\uparrow \downarrow) \\
\text { NIR }\end{array}$ \\
AFDM & PGS NIR 2 $\mu 2$ & $900-2200$ & 256 & $9-16$ & Actinic flux density $(\uparrow \downarrow)$ \\
\hline & MCS UV/VIS & $280-700$ & 512 & $2-3$ & Irradiance $(\downarrow)$ \\
CORAS & MCS UV/VIS & $280-1050$ & 1024 & nctinic fux density $(\downarrow)$ \\
& CG-4 & $4000-42000$ & n/a & Irradiance $(\uparrow \downarrow)$ \\
\hline
\end{tabular}

(2001), Wendisch and Mayer (2003), Wendisch et al. (2004) and Jäkel et al. (2005). The SMART-Albedometer can be adapted to perform different types of atmospheric radiation measurements. In the configuration applied during SAMUM, it comprised a set of six spectrometers (manufactured by Carl Zeiss MicroImaging GmbH, Jena, Germany) that cover almost the entire solar spectrum of solar radiation (from 290 to $2200 \mathrm{~nm}$ ). The spectrometers are connected to specific optical inlets (sensor heads) for the measurement of different radiometric quantities. During the SAMUM experiment, the SMART-Albedometer was operated with optical inlets for the detection of upwelling and downwelling spectral irradiances $F_{\lambda}$ and actinic flux density. The spectral range and resolution of the components of the SMART-Albedometer in its SAMUM configuration are listed in Table 2.

The Zeiss spectrometers are MultiChannel Spectrometers (MCS) for the spectral range from 290 to $1000 \mathrm{~nm}$ (henceforth referred to as VIS) and Plain-Grating Spectrometers (PGS) for the near-infrared spectral range from 900 to $2200 \mathrm{~nm}$ (henceforth NIR). The photons collected by the optical inlets are led to the spectrometers through optical fibres and enter the spectrometer through a cross-section converter slit. Then they are spectrally dispersed by an aberration-corrected grating and detected by photodiode arrays (PDA; manufactured by Hamamatsu, Japan). The electronically amplified signal is recorded and saved on hard disk by LABVIEW software.

The optical connection to the NIR spectrometers is regularly closed by a mechanical shutter during the flight for real-time measurements of the PGS dark signal. The PGS dark signal is of the same order of magnitude as the radiation signal and shows fluctuations that have to be continuously recorded to obtain noise-corrected data. The shutter (manufactured by Ocean Optics BV, the Netherlands) is controlled by the spectrometer software. The NIR measurements undergo a cycle of three subsequent dark measurements (shutter closed) followed by 11 scans with open shutter. Each scan lasts between 0.5 and $1.0 \mathrm{~s}$, depending on the integration time required.

The dark signal of the VIS spectrometers is not only lower but also more stable, and was determined from the signal at wavelengths below $300 \mathrm{~nm}$ where the atmospheric radiation can be expected to be zero. A shutter was therefore not necessary for the VIS spectrometers.

The optical inlets were mounted on the top and the bottom of the Partenavia aircraft on a horizontal levelling system that has been developed jointly by the IfT and enviscope $\mathrm{GmbH}$ (Frankfurt am Main, Germany) and is described in detail by Wendisch et al. (2001). This platform keeps track of the aircraft attitude (roll and pitch angles) with an artificial horizon system (AHS). The AHS data are used to horizontally align the optical inlets. The unavoidable temporal drift of the AHS is corrected by signals received from the Global Positioning System (GPS). Two GPS antennae on the front and rear roof of the aircraft are used. Horizontal stabilization is achieved with an accuracy of better than $\pm 0.2^{\circ}$ with respect to the Earth-fixed coordinate system over a range of pitch and roll angles of up to $\pm 6^{\circ}$. The temporal response of the system is fast enough even for turbulent atmospheric conditions (response time $43 \mathrm{~ms}$, maximum angular velocity $3^{\circ} \mathrm{s}^{-1}$ ). With this stabilization system, uncertainties in the measured irradiances due to horizontal misalignment are estimated to be less than $1 \%$ for solar zenith angles of up to $70^{\circ}$; see (Wendisch et al., 2001).

The radiation instruments have been calibrated with a 1000W standard calibration lamp (traceable to the standards of the National Institute of Standards and Technology, NIST) in the laboratory. Systematic changes due to the integration on the aircraft and possible changes between the flights have been tracked and corrected by transfer-calibration measurements with an integrating sphere after each flight.

An instrument (similar to ours) for airborne measurements of the spectral surface albedo is the Solar Spectral Flux Radiometer (SSFR) which covers the wavelength range from 350 to $2100 \mathrm{~nm}$ (Pilewskie et al., 2003).

\subsection{Ground-based radiation measurements}

The Compact Radiation Measurement System (CORAS) operated almost continuously from 19 May to 5 June 2006 at Ouarzazate airport (at coordinates $30.93^{\circ} \mathrm{N}, 6.91^{\circ} \mathrm{W}$ ). CORAS measured downwelling spectral irradiance $F_{\lambda}^{\downarrow}$ and the downwelling spectral actinic flux density in the wavelength range from 280 


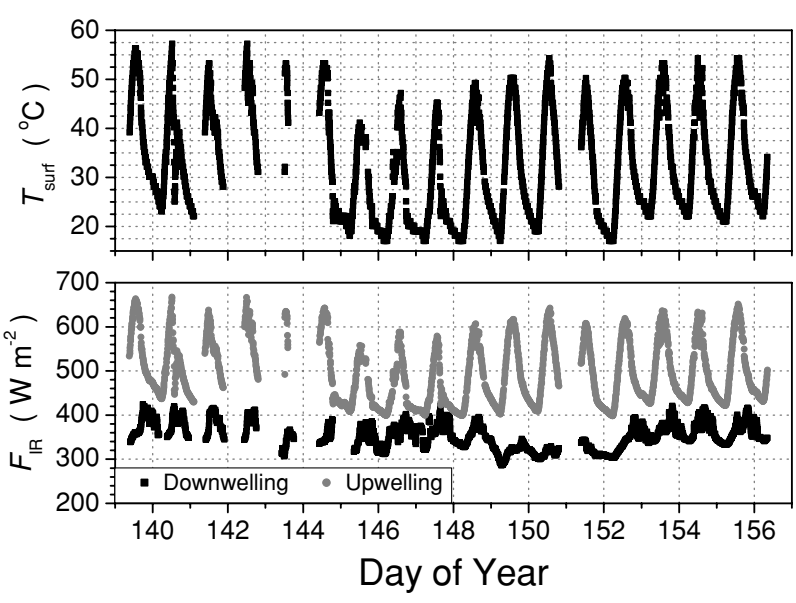

Fig. 1. Time-series of the surface temperature (upper panel) and of the upwelling (lower panel; grey) and downwelling (black) broad-band thermal radiation, measured by pyrgeometers at Ouarzazate airport. Day of year 139 corresponds to 19 May; 152 is 1 June; 156 is 5 June, 2006.

to $1050 \mathrm{~nm}$ by a Zeiss MCS-type spectrometer (see also Table 2), as well as downwelling and upwelling broad-band thermal infrared radiations by CG 4 pyrgeometers (4-42 $\mu$ m; manufactured by Kipp \& Zonen, Delft, the Netherlands). A time-series of the downwelling irradiance at $500 \mathrm{~nm}$ is shown in the work by Knippertz et al. (2008). Time-series of the upwelling and downwelling thermal infrared radiation as well as the derived surface temperature are shown in Fig. 1. An emissivity of 0.97 has been assumed (Ansmann et al., 2008). The usual daily cycle is interrupted by rainfall events which cool the surface and hence the upwelling thermal emission. Such an event took place on 20 May, and a series of strong precipitation events from 24 May to 27 May leads to a considerable reduction of the surface temperature on these days. Also the following 2 days are affected before soil moisture has evaporated and surface temperatures have recovered. Data presented in this paper are only from days not affected by rainfall.

\subsection{Aerosol and meteorological measurements}

Near Tinfou in the Zagora basin (coordinates $30.23^{\circ} \mathrm{N}, 5.61^{\circ} \mathrm{W}$ ), a number of instruments for measurements of optical properties of dust particles have been operated within SAMUM. The dustparticle single-scattering albedo and asymmetry parameter used in this paper have been determined from PM10 measurements of the absorption and scattering coefficients as well as the size distribution (for details see Schladitz et al., 2008). Vertical profiles (down to $250 \mathrm{~m}$ above ground) of the extinction coefficient have been obtained from the Lidar measurements of the Portable Lidar System (POLIS, Heese et al., 2002) of the University of Munich which operated at Ouarzazate airport. As an alterna- tive, the dust-layer height obtained from measurements of the six-wavelength Backscatter Extinction lidar-Ratio Temperature Humidity profiling Apparatus (BERTHA, Tesche et al., 2008) is available. Due to overlap, BERTHA profiles start only at $2 \mathrm{~km}$ above ground (which is above the usual flight altitude of the Partenavia) and are therefore not suitable for the atmospheric correction algorithm for our data.

Furthermore, multiwavelength AOD measurements from the sun photometers operated at Ouarzazate airport (Tesche et al., 2008) and at the Tinfou station (von Hoyningen-Huene et al., 2008) and derived Ångström parameters have been used for the description of the aerosol layer. The measured values of AOD and $\omega_{0}$ used in the radiative transfer modelling are listed in Table 4.

Data for the vertical profile of air pressure, temperature and humidity are obtained from radiosondes launched twice a day at Ouarzazate airport (Ansmann et al., 2008; Tesche et al., 2008). In this work, data from the first launch of each day are used which occurred around 10-11 UTC, that is, during the flight time of the Partenavia aircraft.

\section{Radiative transfer model}

For radiative transfer calculations the software package LIBRADTRAN, described by Mayer and Kylling (2005), was applied. The radiative transfer equation is solved by the discrete-ordinate method in the plane-parallel DISORT2 algorithm by Stamnes et al. (1988; six streams). For gas absorption the parametrization SBDART/LOWTRAN by Ricchiazzi et al. (1998) was selected. LIBRADTRAN uses input data of the atmosphere, surface properties, and extraterrestrial radiation to calculate radiation quantities at arbitrary altitudes within the atmosphere. For the calculation the atmosphere is divided in 88 layers.

LIBRADTRAN was supplied with as many measured input parameters as possible. Data for which measurements were unavailable are replaced by standard assumptions. Daily radiosonde launches provided vertical profiles of air pressure, temperature and humidity. The spectral AOD is included in form of Ångström parameters derived from ground-based multiwavelength AOD measurements. AOD data either from Ouarzazate airport or from the SAMUM site Tinfou have been used accordingly to the aircraft location, with the division running along the mountain range between the two regions. The vertical profile of the aerosol extinction coefficient is derived from POLIS data (cf. Section 2.3). The dust single-scattering albedo and the asymmetry parameter were derived from ground-based measurements at Tinfou (Schladitz et al., 2008). The extraterrestrial irradiance is corrected to the actual Earth-Sun distance. The solar zenith angle is calculated using the geographic coordinates, date and local time. Daily ozone column concentrations have been taken from the Ozone Monitoring Instrument (OMI; cf. Levelt et al., 2006). On 19 May, they amounted to 289-292 DU in the measurement region. All model output is convoluted with the 

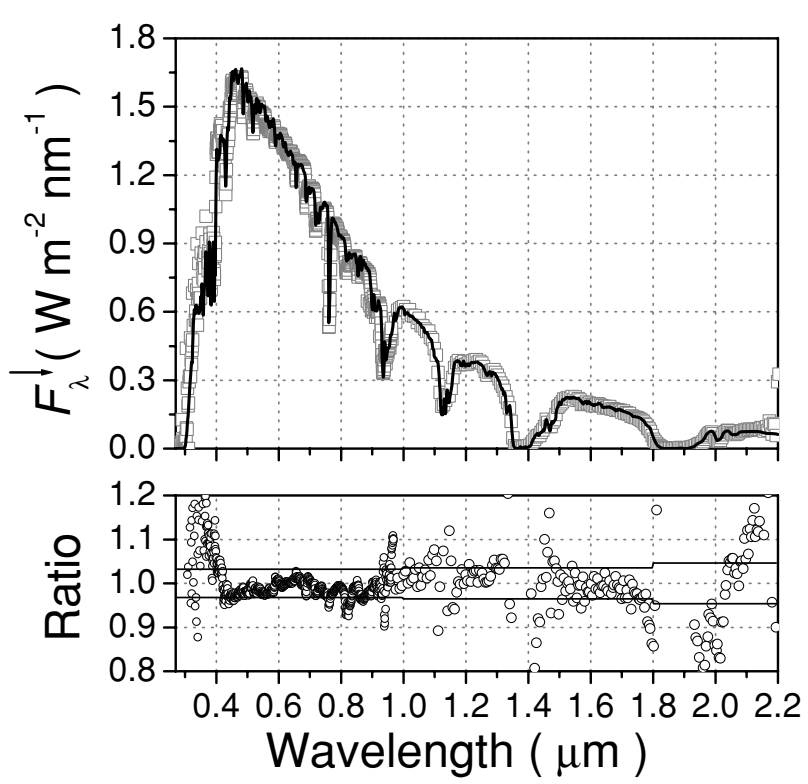

Fig. 2. Measured (open symbols, grey) and modelled (line) instantaneous downwelling irradiance for the first Partenavia flight on 19 May 2006. The lower panel shows the ratio between the results of measurement and model (open circles) in comparison to the measurement uncertainty (solid lines).

instrument slit function to match the spectral resolution of the SMART-Albedometer.

For simulations of thermal infrared radiation, the optical properties of the dust encountered during SAMUM are extrapolated to thermal infrared wavelengths by applying spectral ratios from d'Almeida et al. (1991) to the values that have been determined in the solar spectral range. The surface temperature is determined from pyrgeometer measurements (see Fig. 1).

\section{Measured and simulated spectral irradiances}

\subsection{Airborne radiation data}

To check the consistency of the calibration and the postcampaign processing of the measured data, the obtained downwelling irradiance has been compared to the output of the radiative transfer model. In the model, geometric and atmospheric parameters have been set to their actual measured values. Fig. 2 shows this comparison for the 'golden day' 19 May 2006, on which the largest possible set of measured parameters was available. In most parts of the spectral range, the measured and the modelled irradiance agree with each other in the limits of measurement uncertainty. Exceptions are (1) the water-vapour absorption bands and (2) the spectral range below $400 \mathrm{~nm}$ and above $2100 \mathrm{~nm}$. The former (1) show large deviations because of low radiation levels and a particularly high sensitivity to uncertainties in the radiosonde humidity data as well as to geographic variations (see also Section 5.1); they have therefore
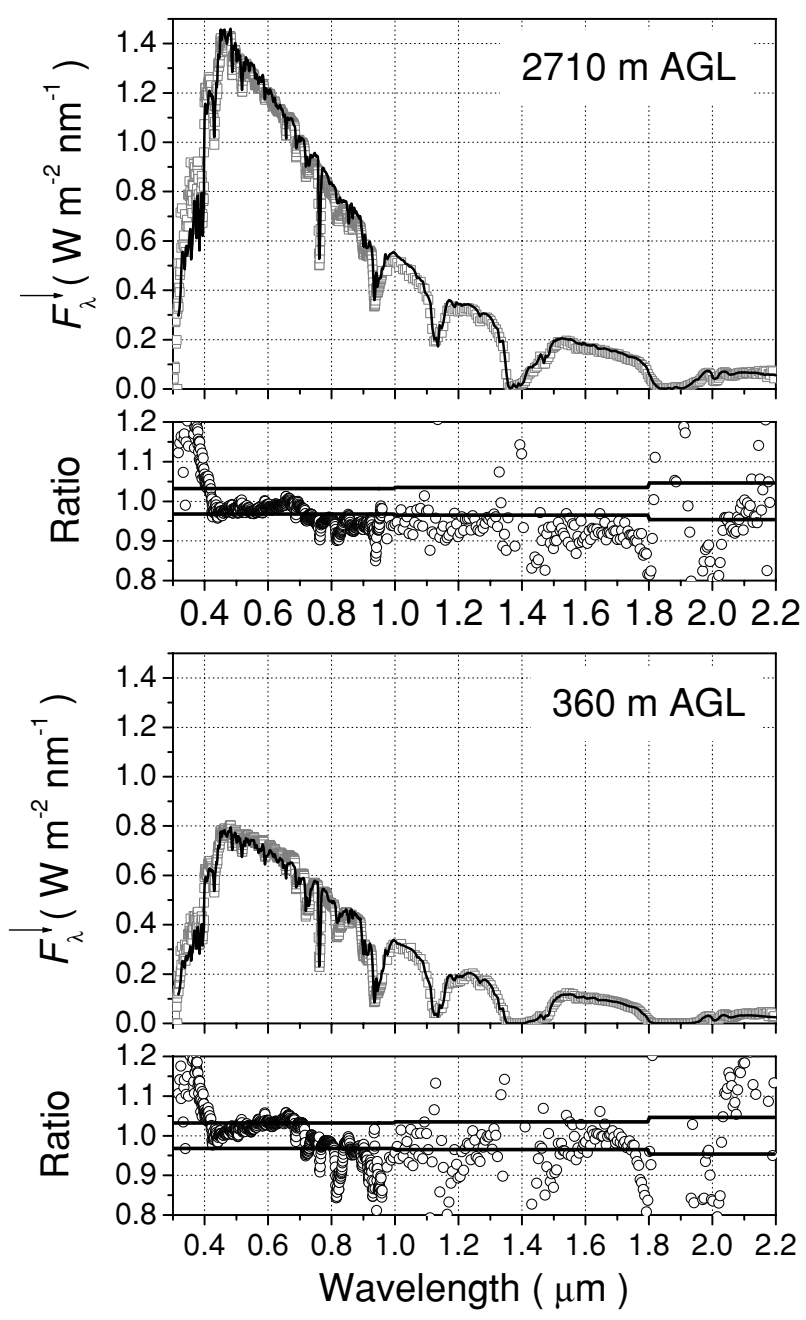

Fig. 3. Measured (open symbols) and modelled (line) instantaneous downwelling irradiance for the Partenavia flight on 3 June, 2006, in the Zagora basin at a flight altitude of $2710 \mathrm{~m}$ (upper panels) and $360 \mathrm{~m}$ (lower panels) above ground. The secondary panels show the ratio between measurement and model result (open circles) in comparison to the measurement uncertainty (solid lines).

been excluded from further analysis. The large deviations below $400 \mathrm{~nm}$ and above $2100 \mathrm{~nm}$ are caused by low raw-data levels because of the transmission properties of the optical fibres; combined with the lower output of the calibration lamp at these wavelengths this leads to the noise in the derived irradiance data.

Two more comparisons are shown in Fig. 3 with the measured and modelled irradiance for 3 June 2006. The radiation measurements were performed in the Zagora basin while the vertical profile (Fig. 4) of the aerosol was determined by POLIS in Ouarzazate, at a distance of approximately $100 \mathrm{~km}$. The aerosol optical depth, however, was scaled to that measured at the Tinfou station in the Zagora basin $(0.86$ at $500 \mathrm{~nm})$. The larger difference between measured and modelled irradiance is due to spatial 


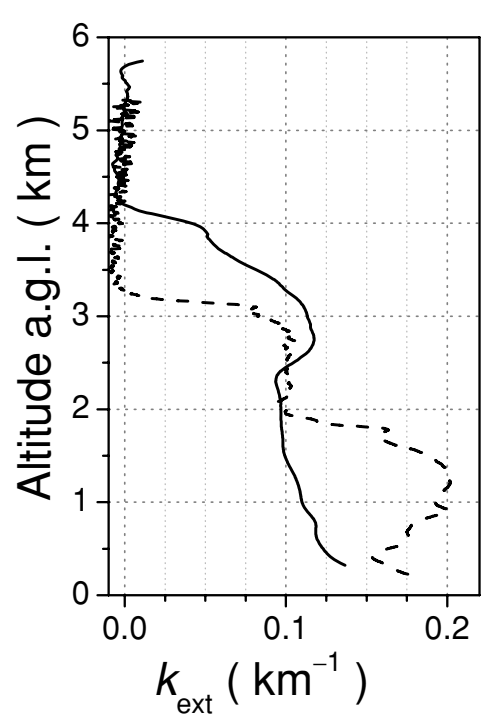

Fig. 4. Vertical profiles of the aerosol extinction coefficient $k_{\text {ext }}$ measured by POLIS in Ouarzazate on 19 May (solid line) and 3 June 2006 (dashed line).

variations of the vertical dust profile that cannot be accounted for in the model. ${ }^{1}$ At a flight altitude of $2710 \mathrm{~m}$ above ground ( $790 \mathrm{~m}$ below the assumed dust-layer boundary), the modelled downwelling irradiance does not agree with the measured irradiance within the uncertainty limits. At a lower altitude $(360 \mathrm{~m}$ above ground) most of the dust layer is above the aircraft, hence the shape of the assumed vertical profile of the aerosol is less important than the measured total aerosol optical depth. The agreement between model and measurement is better than at the high flight altitude at wavelengths outside water-vapour absorption bands. Inside the absorption bands, however, it is worse. This indicates that the water-vapour column in the Zagora basin, especially in the lowest atmospheric layers, is poorly represented by the radiosonde data from Ouarzazate at $100 \mathrm{~km}$ distance. Unfortunately, no better data are available, as no radiosounding was performed in the Zagora basin.

\subsection{Radiation at ground level}

The same procedure has been applied to the ground-based CORAS irradiance data (not shown). Here deviations are below $5 \%$ between 480 and $925 \mathrm{~nm}$, with the exception of the oxygen and water-vapour absorption bands (at 680, 720, 760 and $820 \mathrm{~nm}$ ). For wavelengths below $480 \mathrm{~nm}$, the difference increases (to $10 \%$ at $400 \mathrm{~nm}$ and $40 \%$ at $300 \mathrm{~nm}$ ) for the same reasons as for the airborne measurements shown in the previous

\footnotetext{
${ }^{1}$ Lidar dust profiles have been found to be similar in Ouarzazate (BERTHA) and Tinfou (temporary relocation of POLIS) on 28 May 2006 (B. Heese, personal communication, 2008). But that depends on meteorological conditions which varied during SAMUM, see Knippertz et al. (2008).
}

paragraph (low signal levels). For wavelengths above $925 \mathrm{~nm}$, the difference is strongly increased due to the water-vapour absorption band there, but drops to below $10 \%$ again above $980 \mathrm{~nm}$.

\section{Spectral surface albedo}

\subsection{Methodology}

Solar irradiance reflected from the surface is modified on its way to the aircraft by absorption and scattering processes in the atmospheric layer below the aircraft. Therefore, the surface albedo can only be measured if this influence is accounted for and corrected. This correction is performed with the radiative transfer model and requires knowledge of the meteorological and aerosol optical properties of the atmosphere. Much of this data has been measured during SAMUM (cf. Section 2.3). For the derivation of the surface albedo $\rho_{\lambda}(z=0)$ from the airborne irradiance measurements, the iterative extrapolation algorithm proposed by Wendisch et al. (2004) is applied. This algorithm starts with the albedo measured at flight altitude which is used as a 'first guess' of the surface albedo in the first iteration, and the irradiance field is calculated. The ratio of the 'modelled' albedos at the surface and at flight level is used to obtain the 'assumed' surface albedo for the next iteration step $n+1$ :

$\rho_{n+1, \lambda}\left(z_{0}\right)=\rho_{\text {meas }, \lambda}\left(z_{\mathrm{F}}\right) \frac{\rho_{n, \lambda}\left(z_{0}\right)}{\rho_{n, \lambda}\left(z_{\mathrm{F}}\right)}$.

Here $z_{0}$ is at the surface and $z_{\mathrm{F}}$ is the flight altitude and $\rho_{n, \lambda}$ is the calculated albedo in the $n$th iteration step. As the iteration proceeds, the resulting surface albedo converges to the true surface albedo. The algorithm is stopped when $\rho_{n+1, \lambda}$ and $\rho_{n, \lambda}$ do not differ by more than $1 \%$. The speed of convergence is generally fast but depends on how accurately the input data for meteorological and aerosol optical properties describe the actual situation. In the wavelength range of the VIS spectrometers, convergence was achieved after five iterations in two thirds of all cases. In some cases, up to 30 iterations were required. This indicates that the input data which were measured only at two locations (Ouarzazate and Tinfou) did not accurately enough describe the conditions at those locations on the flight path. In the range of the NIR spectrometers (970-2200 nm), however, convergence was achieved even faster, as the atmosphere-radiation interaction is weaker than in the VIS range. Almost always only 2-3 iterations were necessary in the NIR.

Sensitivity studies (see Section 5.2 ) revealed that the retrieved surface albedo at wavelengths in the water-vapour absorption bands is very sensitive to variations of the flight altitude assumed in the study. This means that spatial variations of the vertical water-vapour profile, for example, due to the distance between aircraft and radiosonde, lead to huge uncertainties in these bands. The obtained surface-albedo spectra are so noisy in these bands that no meaningful surface albedo can be 
derived. This is even more true in those water-vapour absorption bands around 1350 and $1900 \mathrm{~nm}$ where irradiance in the lower troposphere is almost completely attenuated. Therefore, at these wavelengths no measurement of the surface albedo is possible. Hence, the following wavelength bands have been excluded from the surface-albedo results (in nm): 750-775, 930-1008, 1099-1177, 1320-1490, 1775-1950.

Also the spectral range below $317 \mathrm{~nm}$ has been excluded due to low irradiance levels and accordingly noisy ratios. The darksignal noise of the spectrometers has a stronger impact there on the net signals of the downwelling and even more on the (weaker) upwelling irradiance, and the noise of these two quantities is even more evident in their ratio. This is also the case above $1950 \mathrm{~nm}$, but noise levels are lower there.

\subsection{Measurement uncertainties}

The uncertainty of the derived surface albedo is estimated as a combination of the uncertainty of the irradiance measurement and the impact of uncertainties in atmospheric parameters that are used in the extrapolation algorithm. For the irradiance the following error sources are relevant: the radiometric uncertainty of the calibration lamp (specified by the manufacturer as $1.7 \%$ between 250 and $1800 \mathrm{~nm}$ and $3.4 \%$ between 1800 and $2200 \mathrm{~nm}$ ); the geometric uncertainty in the determination of the effective receiving plane of the optical inlets (estimated to yield an irradiance uncertainty of $\pm 1 \%$ ); the determination of the cosine correction factors of the optical inlets (yields $\pm 1 \%$ ); the angular uncertainty of the horizontal stabilization platform on the aircraft (yields $\pm 1 \%$ ); fluctuations of the dark signal that are not accounted for in the data evaluation process (yields up to $0.7 \%$ for VIS and up to $1.5 \%$ for NIR) and the calibration stability during the field campaign which was monitored with a portable integrating sphere and amounts to $\pm 2 \%$. As each error source contributes independently of the others, these uncertainties yield the total irradiance uncertainty by Gaussian combination. It ranges from $3.2 \%$ to $4.6 \%$ depending on wavelength (see Table 3).

For an estimate of the uncertainties due to the surface-albedo extrapolation algorithm, a series of sensitivity studies has been performed in which the input parameters were varied in the algorithm. The range of variation has been chosen to reflect the variations of the measured parameters on 19 May 2006, either with time or space: The single-scattering albedo and the asymmetry parameter have been measured at the ground station in Tinfou, and varied in the course of the day. Accordingly variations of $5 \%$ and $10 \%$ have been assumed in the calculations. For the AOD its geographical variation in the measurement area as observed by MISR (around $\pm 30 \%$ ) has been taken into account. For the flight altitude, an uncertainty of $\pm 30 \mathrm{~m}$ has been assumed. All these parameters have the strongest influence at wavelengths below $600 \mathrm{~nm}$, which agrees with the observation
Table 3. Uncertainties (in \%) of the measured irradiance (upper half) and of the retrieved surface albedo

\begin{tabular}{lccccc}
\hline Error & I & II & III & IV & V \\
\hline Calibration lamp & 1.7 & 1.7 & 1.7 & 1.7 & 3.4 \\
Receiving plane & 1 & 1 & 1 & 1 & 1 \\
Cosine correction & 1 & 1 & 1 & 1 & 1 \\
Horizontal stabilization & 1 & 1 & 1 & 1 & 1 \\
Dark signal & $<0.7$ & $<0.7$ & $<0.7$ & $<1.5$ & $<1.5$ \\
Calibration stability & 2 & 2 & 2 & 2 & 2 \\
Total irradiance uncertainity & 3.2 & 3.2 & 3.2 & 3.5 & 4.6 \\
\hline$F^{\downarrow}$ & 3.2 & 3.2 & 3.2 & 3.5 & 4.6 \\
$F^{\uparrow}$ & 3.2 & 3.2 & 3.2 & 3.5 & 4.6 \\
$\omega_{0}$ & 1.2 & 0.8 & 0.5 & 0.5 & 0.5 \\
AOD & 0.8 & 0.8 & 0.2 & 0.2 & 0.2 \\
$g$ & 6 & 1.5 & 0.3 & 0.3 & 0.3 \\
$h$ & 4 & 0.5 & 0.2 & 0.2 & 0.2 \\
Total surface -albedo uncertainity & 8.6 & 4.9 & 4.6 & 5.0 & 6.5 \\
\hline
\end{tabular}

Note: Errors relevant for irradiance: Calibration lamp, receiving plane, cosine correction, horizontal stabilisation, dark-signal fluctuations and calibration stability. The uncertainty of the surface albedo is a Gaussian combination of the irradiance uncertainty and the variability of the surface-albedo extrapolation algorithm when different input parameters (single-scattering albedo $\omega_{0}$, AOD, asymmetry parameter $g$, flight altitude $h$ ) are varied (see text). The spectral range from $317 \mathrm{~nm}$ to $2200 \mathrm{~nm}$ has been divided into five intervals (I-V). I: $317-400 \mathrm{~nm}$. II: 400-600 nm. III: $600-1000 \mathrm{~nm}$. IV: $1000-1800 \mathrm{~nm}$. V: $1800-2200 \mathrm{~nm}$. All values are given in percent.

of much faster convergence of the surface-albedo retrieval algorithm in the NIR range.

All uncertainties are summarized in Table 3. It follows for the surface albedo that in most parts of the measurement range its uncertainty lies between $4.6 \%$ and $5.0 \%$, while it rises to $6.5 \%$ for wavelengths above $1800 \mathrm{~nm}$ and to $8.6 \%$ below $400 \mathrm{~nm}$.

\subsection{Typical spectra of surface albedo}

The Partenavia aircraft has conducted 13 successful measurement flights from 19 May to 6 June 2006. See Table 4 for the flight parameters and Fig. 5 for a geographic overview. A coloured topographic map of the region is shown by Knippertz et al. (2007). Different surface types were covered. Most of the terrain in the Ouarzazate and Zagora basins is a brown-red stone desert (hamada). But also a number of oases, especially in the Drâa and Dadès valleys, and the dry Iriki salt lake near the Algerian border have been overflown. Some typical surface-albedo spectra are shown in Fig. 6.

The most prominent type of spectra in the experiment region is the smooth type with little features, typical for the hamada ground. This hamada spectrum (Fig. 6a) shows an 
Table 4. The 13 flights of the Partenavia D-GERY during SAMUM, all from and to Ouarzazate

\begin{tabular}{|c|c|c|c|c|c|}
\hline Date (2006) & TOT & Duration & MISR & AOD-O & $\begin{array}{c}\text { AOD-Z } \\
\omega_{0}\end{array}$ \\
\hline 19 May & $10: 14$ & $1 \mathrm{~h} 52^{\prime}$ & $11: 11$ & 0.41 & $\begin{array}{l}0.46 \\
0.95\end{array}$ \\
\hline 20 May & $10: 15$ & $2 \mathrm{~h} 34^{\prime}$ & & 0.51 & $\begin{array}{l}0.60 \\
0.94\end{array}$ \\
\hline 21 May & 08:00 & $2 \mathrm{~h} 10^{\prime}$ & & 0.48 & $\begin{array}{l}0.46 \\
0.93\end{array}$ \\
\hline 24 May & $07: 56$ & $1 \mathrm{~h} 57^{\prime}$ & & 0.41 & $\begin{array}{l}0.78 \\
0.95\end{array}$ \\
\hline 25 May & 09:20 & $2 \mathrm{~h} 40^{\prime}$ & & 0.54 & $\begin{array}{l}1.23 \\
0.95\end{array}$ \\
\hline 27 May & 09:01 & $3 \mathrm{~h} 32^{\prime}$ & & 0.53 & $\begin{array}{l}0.77 \\
0.96\end{array}$ \\
\hline 28 May & $09: 33$ & $2 \mathrm{~h} 37^{\prime}$ & $11: 05$ & 0.35 & $\begin{array}{l}0.47 \\
0.96\end{array}$ \\
\hline 30 May & 09:56 & $2 \mathrm{~h} 07^{\prime}$ & & 0.07 & $\begin{array}{l}0.21 \\
0.90\end{array}$ \\
\hline 2 June & 09:12 & $2 \mathrm{~h} 58^{\prime}$ & & 0.22 & $\begin{array}{l}0.65 \\
0.95\end{array}$ \\
\hline 3 June & $07: 31$ & $2 \mathrm{~h} 52^{\prime}$ & & 0.42 & $\begin{array}{l}0.86 \\
0.96\end{array}$ \\
\hline 4 June & 10:07 & $1 \mathrm{~h} 19^{\prime}$ & $11: 11$ & 0.45 & $\begin{array}{l}0.53 \\
0.96\end{array}$ \\
\hline 5 June & $07: 59$ & $3 \mathrm{~h} 17^{\prime}$ & & 0.33 & $\begin{array}{l}0.43 \\
0.95\end{array}$ \\
\hline 6 June & 08:08 & $3 \mathrm{~h} 33^{\prime}$ & & 0.48 & $\begin{array}{l}0.48 \\
0.94\end{array}$ \\
\hline
\end{tabular}

Note: Given is the day, the take-off time (TOT) in UTC (=local time), the flight duration, the time of the MISR satellite overpasses, the aerosol optical depth at $500 \mathrm{~nm}$ during the flight time as measured by the sun photometers in Ouarzazate (AOD-O) and Tinfou/Zagora (AOD-Z) as well as the aerosol single-scattering albedo $\omega_{0}$ measured at $530 \mathrm{~nm}$ in Tinfou. All flights were conducted before noon to avoid the daily cloud formation around noon.

increase throughout the visible spectral range, from values well below 0.05 in the ultraviolet to values around $0.2-0.3$ at $900 \mathrm{~nm}$. This includes an enhancement of the red colour range (600$800 \mathrm{~nm}$ ). Above $800 \mathrm{~nm}$, a plateau is observed up to $2200 \mathrm{~nm}$ with small slope which is mostly slightly positive but in a few cases also slightly negative. When flying over vegetation in the oases (Fig. 6b), characteristic changes occur in the albedo spectrum: A strong step around $700 \mathrm{~nm}$, the so-called vegetation step, or red edge, appears (this is natural protection against plant damage caused by NIR radiation) and is accompanied by a stepwise decrease of the surface albedo between 1000 and $2200 \mathrm{~nm}$ (due to water). Vegetated surfaces appear darker below $700 \mathrm{~nm}$ compared to the surrounding barren ground.

A mixture of these two types of spectra is shown in (Fig. 6c). In this case, the aircraft was above a small oasis on the edge of

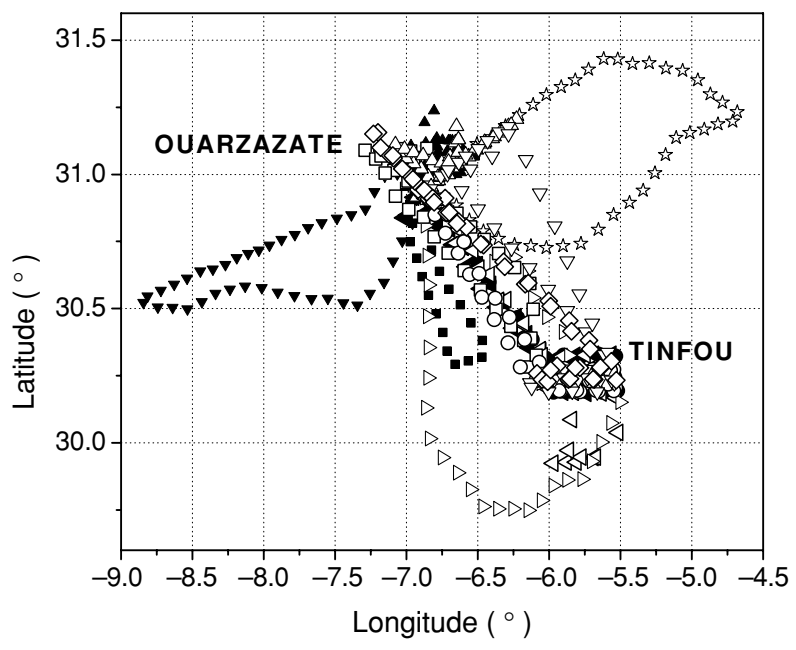

Fig. 5. Map of all 13 Partenavia flights during the SAMUM campaign. 19 May 2006—solid squares, 20 May—solid circles, 21 May—solid triangle up, 24 May—solid triangle down, 25 May—solid triangle left, 27 May—open triangle left, 28 May—open triangle right, 30 May—asterisk, 2 June—open square, 3 June-open circle, 4 June-open triangle up, 5 June-open triangle down, 6 June-open diamond. All flights start at Ouarzazate airport (coordinates $30.9^{\circ} \mathrm{N}$, $6.9^{\circ} \mathrm{W}$ ), and many targeted the Tinfou ground station near Zagora (coordinates $30.24^{\circ} \mathrm{N}, 5.61^{\circ} \mathrm{W}$ ).

the Atlas mountains. The field of view was dominated by barren ground, and in consequence the surface-albedo spectrum is dominated by the shape of the hamada spectrum. However, the vegetation step, albeit small, is clearly visible at wavelengths around $700 \mathrm{~nm}$, showing the high sensitivity of the surface albedo to the presence of vegetation in otherwise unvegetated areas.

Figure 6d shows an extreme case of the hamada-type surfacealbedo spectrum. These data have been collected while flying above the dry lake Iriki, a vast, flat dry area to the south of the Zagora basin, covered by layers of salt that have been formed by the evaporation of the River Drâa. This is a bright area clearly visible from space, with surface albedo reaching values around 0.4 in the red $(700 \mathrm{~nm})$ and up to 0.5 around $1.7 \mu \mathrm{m}$.

\subsection{Comparison with satellite data}

The flights on 19 May, 28 May and 4 June coincided with overflights of the Terra satellite of the Earth Observing System (EOS). MISR aboard Terra measures radiances by imaging spectrometers at nine viewing angles and at four wavelengths (446, 558, 672 and $866 \mathrm{~nm})$. The MISR aerosol algorithm aims at a retrieval of the AOD and other aerosol parameters from this multiangular information and with a reduced dependence on uncertain assumptions about the surface albedo. The retrieved aerosol information is then used in a retrieval of the bidirectional reflectance distribution function (BRDF) and subsequently of the 

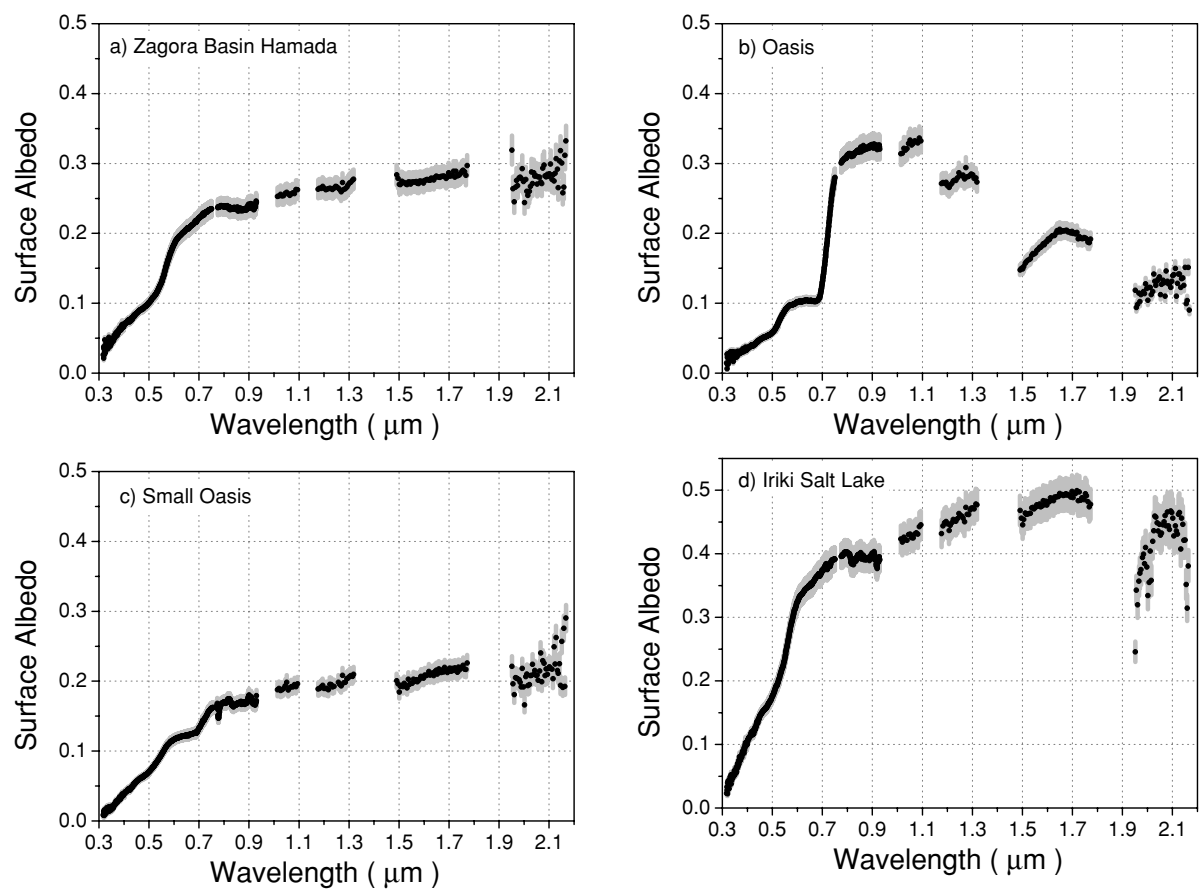

Fig. 6. Some examples of SAMUM albedos. Figure 6a shows a typical surface-albedo spectrum of the red stone-desert (hamada) surface measured in the Zagora basin. The same type of spectrum was found in many parts of the Ouarzazate basin. Figure $6 \mathrm{~b}$ is a typical vegetation spectrum of an oasis in the Dadès valley. Figure 6c was measured over a small oasis in the Atlas mountains with plenty of surrounding hamada in the field of view: even though the spectral shape is dominated by that of barren ground, it clearly shows the vegetation edge at $700 \mathrm{~nm}$. Figure $6 \mathrm{~d}$ is the albedo spectrum of the salt-covered surface of the dry lake Iriki. The measurement uncertainty (Table 3 ) is indicated in grey.

surface albedo at the four MISR wavelengths. MISR-retrieved surface-albedo data are available at $1.1 \mathrm{~km}$ resolution (whereas the aerosol properties are retrieved at $17.6 \mathrm{~km}$ resolution). The field of view of the SMART-Albedometer is usually larger than a MISR pixel, depending on flight altitude. Therefore, each data point of the SMART-Albedometer has been compared to the average of the surface albedo of all MISR pixels that are covered by the albedometer's field of view at that moment.

The difference between the surface albedo derived from the Partenavia measurements $\left(\rho_{\mathrm{GERY}}\right)$ and that derived from the MISR data, $\rho_{\text {MISR }}$, is shown in Fig. 7 as a flight-track timeseries of the ratio $\left(\rho_{\mathrm{GERY}}-\rho_{\mathrm{MISR}}\right) / \rho_{\mathrm{GERY}}$, along with the flight altitude. The relative albedo difference ranges from $+50 \%$ to $-100 \%$. For most of the flight time, the difference is within $\pm 30 \%$, but a few intervals are observed in which the difference is significantly larger (mismatch).

The first mismatch (around 11:15 UTC) is explained by the viewing geometry, as the underlying terrain contains valleys with steep walls in southwest-northeastern direction. With the sun in the southeast and MISR viewing from the east, MISR sees the sunlit northwestern walls but not the shadowed southeastern walls, but the SMART-Albedometer also sees the shadowed areas. This is interpreted by the SMART-Albedometer as a lower surface albedo than that obtained by MISR, hence the large negative peak in Fig. 7. Also, in such a case the resulting

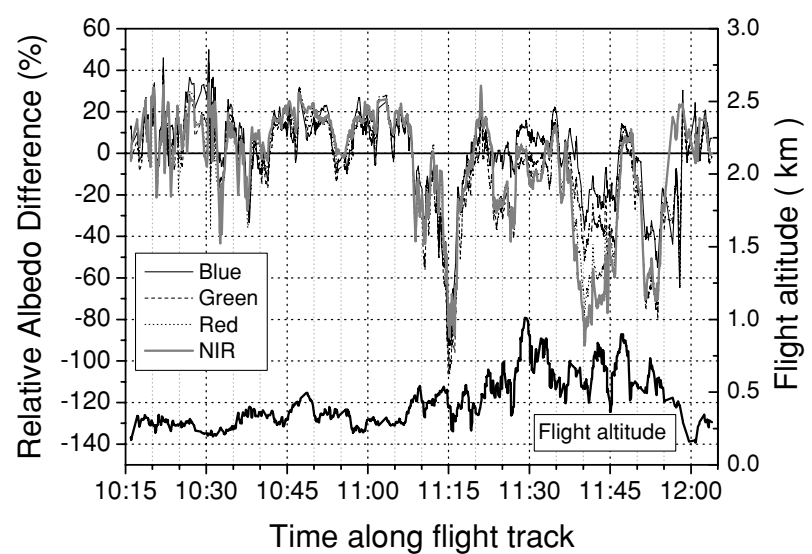

Fig. 7. Difference between the surface albedo of 19 May derived from the SAMUM Partenavia ( $\left.\rho_{\mathrm{GERY}}\right)$ measurements and from MISR $\left(\rho_{\text {MISR }}\right)$, plotted as a time-series of the ratio $\left(\rho_{\mathrm{GERY}}-\rho_{\mathrm{MISR}}\right) / \rho_{\mathrm{GERY}}$ along the Partenavia flight track. The separate lower curve indicates the flight altitude (right $y$ axis). Times are given in UTC.

albedo difference should not be a function of wavelength, and this matches the observation.

The second mismatch (around 11:40 UTC) is wavelengthdependent, with the albedo difference increasing at larger wavelengths. This behaviour indicates that the albedo difference 
cannot be caused by a wrong aerosol model in the retrieval algorithm of the SMART-Albedometer, because the aerosol influence on the retrieved surface albedo is largest in the blue and lowest at larger wavelengths (cf., e.g. Table 3) which would give rise to an opposite behaviour. Instead we refer to Kahn et al. (2005) who in dusty cases found that the AOD difference between MISR and the AERONET reference is largest in the NIR and lower towards the blue which matches our observation. That has been caused by problems in the algorithm choice of the aerosol model, resulting in wrong optical properties (in particular, particle shape and single-scattering albedo). As the retrieved AOD is used for the surface-albedo retrieval of MISR, a poorly retrieved AOD would have similar consequences for the retrieved surface albedo. While the aerosol model in the MISR algorithm has been in general improved since, Kahn et al. (2008) found indications that on some occasions during SAMUM on 19 May 2006, the 'particle property retrieval itself is not well constrained'. This may be due to an inadequate surface model (and the mismatch region has a characteristic wrinkled surface structure different to that before and after the mismatch), or to the aerosol model (subpixel dust storm, e.g.).

The surface albedo retrieved from MERIS data compares well to that presented in this paper at small wavelengths and with respect to the slope, but shows larger deviations above $550 \mathrm{~nm}$ which is identified as one of the problems in the AOD retrieval algorithm of MERIS (Dinter et al., 2008).

\section{Dust radiative forcing}

For SAMUM we assume that the radiative forcing as defined in eq. (2) is solely caused by dust in the troposphere, that is, we may neglect extraterrestrial perturbations by the assumption

$F_{\text {pert }}^{\mathrm{TOA} \downarrow}=F_{0}^{\mathrm{TOA} \downarrow}$

for the irradiance at TOA which leads to the simplification

$\Delta F^{\mathrm{TOA}}=F_{0}^{\mathrm{TOA} \uparrow}-F_{\mathrm{pert}}^{\mathrm{TOA} \uparrow}$.

The unperturbed case (index 0) refers to a dust-free atmosphere.

At the surface, the upwelling radiation is determined by the surface albedo $\rho$ and the downwelling radiation:

$F^{\text {surf } \uparrow}=\rho F^{\text {surf } \downarrow}$

which leads to the simplification

$\Delta F^{\text {surf }}=(1-\rho)\left(F_{\text {pert }}^{\text {surf } \downarrow}-F_{0}^{\text {surf } \downarrow}\right)$.

\subsection{Solar radiative forcing}

Using the LIBRADTRAN radiative transfer model, the solar radiative forcing has been calculated for the dust conditions of 19 May 2006. In this study, the impact of the spatial variability of the underlying surface albedo is investigated. Therefore, the dust layer is assumed to be horizontally homogeneous with

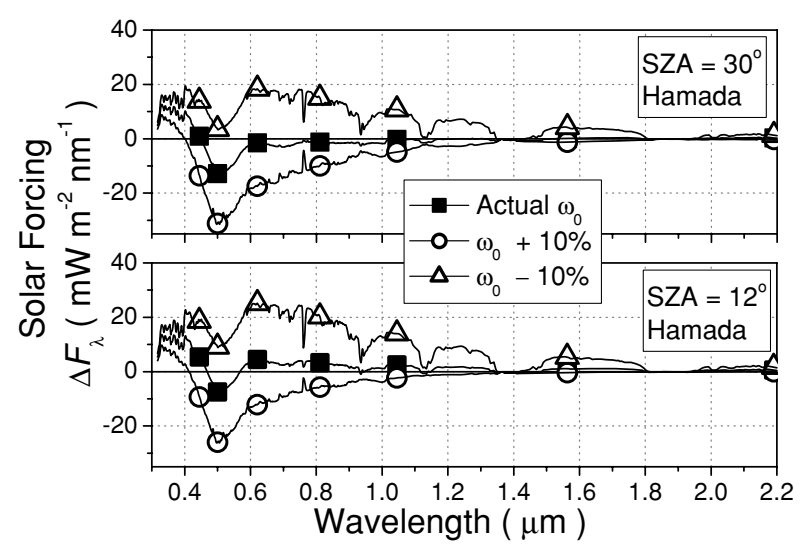

Fig. 8. The spectral solar radiative forcing $\Delta F_{\lambda}$ at TOA calculated for the dust conditions on 19 May 2006, and with variations of the dust single-scattering albedo $\omega_{0}$ of $\pm 10 \%$. The upper and lower panels show the forcing at the start and at end of the 19 May measurement flight, with a solar zenith angle (SZA) of $30^{\circ}$ and $12^{\circ}$, respectively (corresponding to 10:20 and 12:00 UTC). The surface albedo is the hamada standard from Fig. 6a in both panels.

a vertical extinction profile that has been measured in Ouarzazate, while the surface albedo is varied according to the flight measurements. The undisturbed case in these calculations is the same atmosphere model as in the perturbed case, but without any aerosol.

In a first step, the spectral radiative forcing has been calculated for dust over three standard types of surface albedo: the typical hamada surface (Fig. 6a), the extremely bright Iriki salt lake (Fig. 6d) and a vegetation type from an oasis (Fig. 6b). In addition, the single-scattering albedo was varied from the Tinfou values by $\pm 10 \%$. For the typical hamada ground, Fig. 8 shows that the change of the solar zenith angle during the flight gives rise to only a small change in the dust radiative forcing. However, changing the assumed single-scattering albedo of the dust particles has a huge impact: for a strongly absorbing aerosol (reduced $\omega_{0}$ values), the dust leads to positive forcing values in the entire solar spectrum, while almost non-absorbing aerosol (enhanced $\omega_{0}$ values) leads to generally negative forcing values.

If the spectral forcing in the case of $12^{\circ}$ SZA (Fig. 8, lower panel) is integrated over wavelength, we obtain $+2.9 \mathrm{~W} \mathrm{~m}^{-2}$ for the standard $\omega_{0}$ (i.e. a slight warming due to slight absorption by the aerosol), $-5.9 \mathrm{~W} \mathrm{~m}^{-2}$ for increased $\omega_{0}$ (cooling for a purely scattering aerosol) and $+16.5 \mathrm{~W} \mathrm{~m}^{-2}$ for reduced $\omega_{0}$ (warming for stronger absorbing aerosol). The latter agrees notably well with a warming of $17 \mathrm{~W} \mathrm{~m}^{-2}$ which Otto et al. (2008) obtain for the same time (12:00 UTC), but with an even lower $\omega_{0}$ and taking into account particle non-sphericity.

There are indications that the case with reduced $\omega_{0}$ might be more representative. The most recent results for modelling the single-scattering albedo on 19 May 2006, are lower compared to the values obtained from PM10 measurements in 


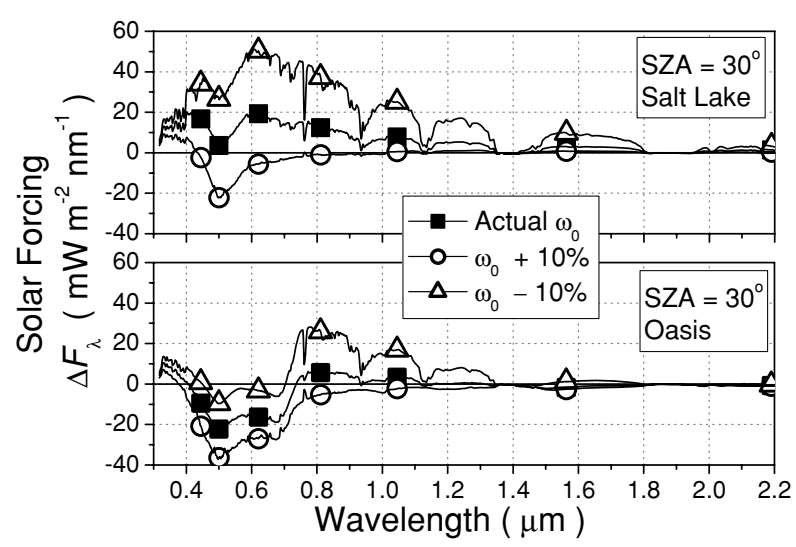

Fig. 9. The same as Fig. 8, but for different assumed surface albedos, and a fixed solar zenith angle (SZA) of $30^{\circ}$. In the upper panel, the salt-lake albedo spectrum of Fig. 6d was used, while the lower panel is based on the oasis-type albedo spectrum of Fig. $6 \mathrm{~b}$. Again, the dust single-scattering albedo $\omega_{0}$ was varied by $\pm 10 \%$.

Tinfou (Schladitz et al., 2008) used for our calculations $\left(\omega_{0}\right.$ $=0.95$ at $\lambda=537 \mathrm{~nm}$ ). Otto et al. (2008) obtain approximately 0.8 at $\lambda=550 \mathrm{~nm}$ for particles with diameters of up to $50 \mu \mathrm{m}$. Wiegner et al. (2008) obtain $\omega_{0}=0.77-0.90$ at $\lambda=532 \mathrm{~nm}$ based on size distributions for particles with diameters of up to $20 \mu \mathrm{m}$, depending on uncertainties in the assumed microphysical properties. Hence, questions remain about the true value of $\omega_{0}$ for Saharan dust. However, two cases of our sensitivity study $\left(\omega_{0}=0.95\right.$ and $\left.\omega_{0}-10 \%=0.855\right)$ cover most of the range of possible values and therefore give an idea about the possible consequences of the $\omega_{0}$ question.

Back to Fig. 8, gas absorption bands (oxygen at $762 \mathrm{~nm}$, water vapour) are always visible and reduce the absolute amount of the dust forcing, as the number of photons that can 'carry' the dust information is reduced. Interestingly, the radiative forcing for the actual SAMUM $\omega_{0}$ values is small in amount and can change its sign in dependence on the otherwise less relevant solar zenith angle.

The influence of the spectral surface albedo is shown in Fig. 9. Strong changes in the surface albedo, as they have been encountered in southeast Morocco, have strong effects on the local TOA radiative forcing. Over the highly reflecting salt surface of the dry lake Iriki, the forcing is generally positive except for extreme low particle absorption coefficients. Over vegetation, however, the low reflectivity at wavelengths below $700 \mathrm{~nm}$ leads to a generally negative TOA forcing in this spectral range, even for the strongly absorbing aerosol type. The large surfacealbedo increase at $700 \mathrm{~nm}$ is clearly reflected in the spectral TOA forcing, as is the decrease between 1 and $2 \mu \mathrm{m}$.

To quantify the broad-band radiative effect of the Saharan dust and to depict its possible ranges, the broad-band solar radiative dust forcing has been calculated along the entire Partenavia flight track (Fig. 10). First, irradiances have been calculated taking into

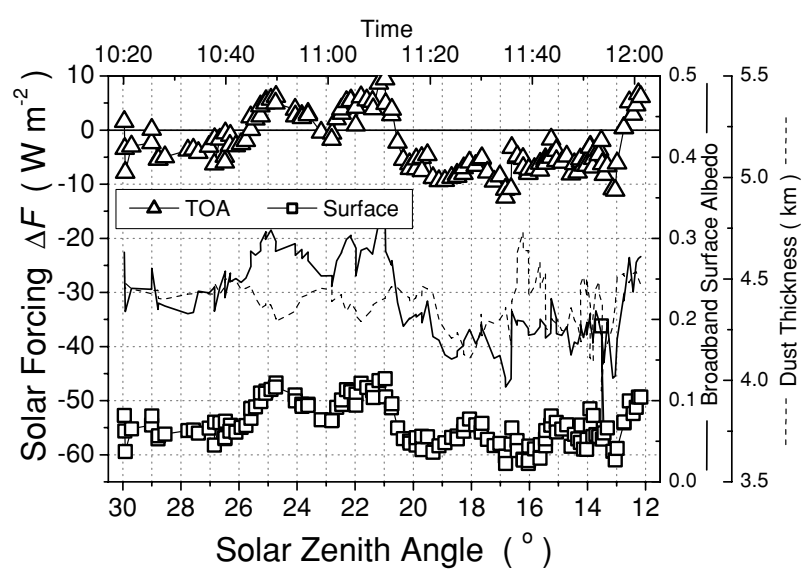

Fig. 10. Integral solar radiative forcing at TOA and the surface along the Partenavia flight track on 19 May 2006. The dust layer was assumed to have a constant boundary height above sea level, so the local dust-layer thickness varies with the surface elevation. The two most influential parameters are shown for comparison: surface albedo (solid line) and dust-layer thickness (dashed line). Variations of the solar zenith angle have only minor influence (not shown). Times are given in UTC.

account all actual variations of the surface albedo, the surface elevation and the solar zenith angle. The forcing was again calculated as the difference of net irradiances between a perturbed (dusty) case and a dust-free but otherwise identical case. The information about the optical properties of the dust (optical depth, single-scattering albedo and asymmetry parameter) have been kept constant for all locations because only the point measurements at Ouarzazate and Tinfou were available. The dust-layer height, however, was modified for each data point, following the surface elevation. This takes the observation into account that the dust top boundary was flat. Fig. 10 shows that most features of the TOA and surface forcing coincide with variations of the surface albedo, but a few peaks - especially of the surface forcing - coincide with variations of the dust-layer thickness. Except for a single point (at a solar zenith angle of $13.5^{\circ}$ ), however, the surface elevation varied not strongly enough to have more influence on the forcing than the surface albedo.

To single out the influence of surface albedo, we have to eliminate this influence of topography and of the varying position of the sun. To this purpose, the calculation has been repeated with both surface elevation and solar zenith angle fixed at average values (Fig. 11). The influence of the variations of the solar zenith angle (which took values between $12^{\circ}$ and $30^{\circ}$ ) is small (not shown). The result in Fig. 11 shows the solar radiative forcing both at TOA and at the surface with variations of only the surface albedo. The solar TOA forcing varies between +10 and $-15 \mathrm{~W} \mathrm{~m}^{-2}$, so even its sign is determined by the surface albedo under the given conditions.

The solar radiative forcing at the surface varies between -45 and $-65 \mathrm{~W} \mathrm{~m}^{-2}$. It is also dominated by the surface albedo, but 


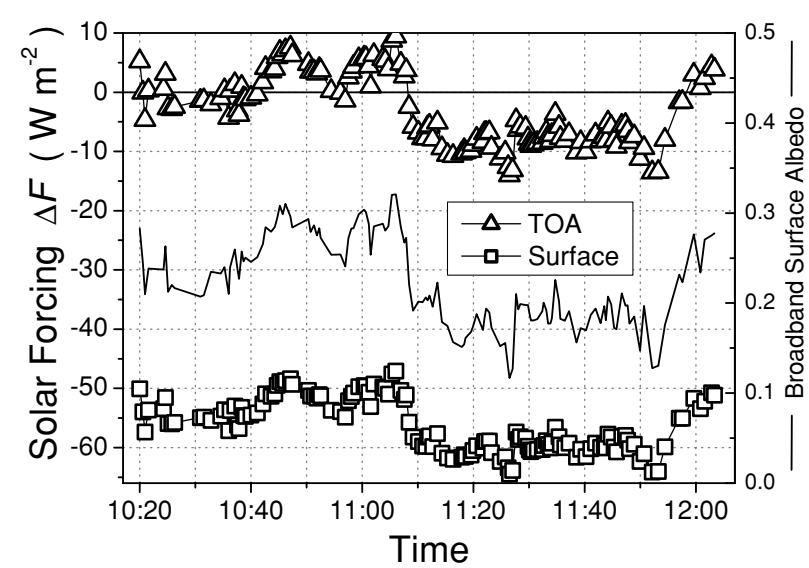

Fig. 11. Integral solar radiative forcing along the Partenavia flight track on 19 May 2006, calculated with the solar zenith angle and the surface elevation fixed to average values $\left(21^{\circ}\right.$ and $1.135 \mathrm{~km}$, respectively; the latter resulting in a dust-layer thickness of $4.5 \mathrm{~km}$ ). Times are given in UTC.

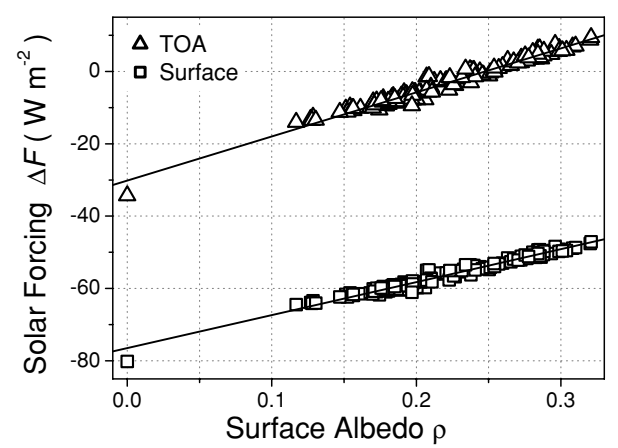

Fig. 12. Correlation plot of the solar radiative forcing in dependence on the surface albedo for the flight on 19 May 2006, based on the calculations with SZA and surface elevation fixed at average values (Fig. 11). An additional hypothetical case with zero surface albedo has been additionally calculated. The linear fits yields the following results: $\Delta F^{\mathrm{TOA}}=-30.2 \mathrm{~W} \mathrm{~m}^{-2}+\left(121.8 \mathrm{~W} \mathrm{~m}^{-2}\right) \rho$ and $\Delta F^{\text {surf }}=$ $-76.5 \mathrm{~W} \mathrm{~m}^{-2}+\left(91.1 \mathrm{~W} \mathrm{~m}^{-2}\right) \rho$.

a comparison of Figs. 10 and 11 shows that the surface forcing is more sensitive to the dust-layer thickness than the TOA forcing.

There is a linear dependence of the solar radiative forcing of Saharan dust on the surface albedo (see Fig. 12). This linearity follows from the basic radiative transfer theory (Chandrasekhar, 1960). The correlation coefficient for the linear fit is 0.98 for $\Delta F$ at both TOA and the surface. The dust radiative forcing at TOA and at the surface grow by 12 and $9 \mathrm{~W} \mathrm{~m}^{-2}$ per 0.1 surfacealbedo increase, respectively.

\subsection{Radiative forcing in the thermal infrared}

The radiative forcing in the thermal infrared is calculated in dependence on the surface temperature. The surface temperature has been derived from the continuous pyrgeometer measure-

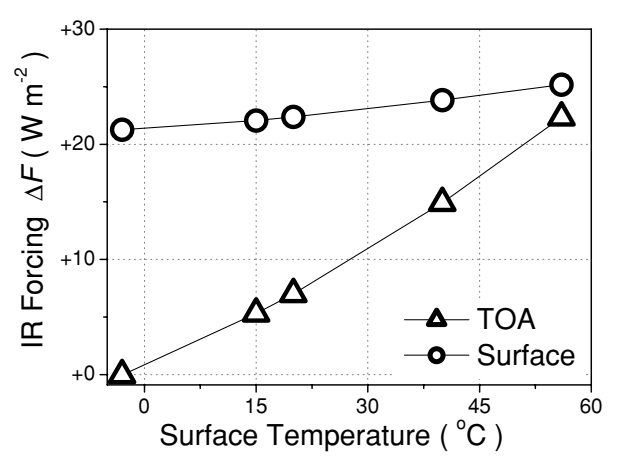

Fig. 13. Integral thermal infrared radiative forcing for the dust conditions of 19 May 2006, and for the surface temperature range during SAMUM: $15^{\circ} \mathrm{C}$ for the coldest night and $56^{\circ} \mathrm{C}$ for a hot noon. An additional case has been calculated which results in zero TOA forcing. This occurs when the surface temperature equals the temperature of the uppermost kilometre of the dust layer.

ments and varied between $15^{\circ} \mathrm{C}$ during the night and maximum values of $56^{\circ} \mathrm{C}$ on clear-sky days. The thermal infrared forcing of the dust layer of 19 May is shown in Fig. 13. At TOA it is strongest when the infrared emission of the surface is strongest, that is, at high surface temperatures, when it reaches $+22 \mathrm{~W} \mathrm{~m}^{-2}$. Assuming the very same dust layer, at night-time surface temperatures the thermal infrared TOA forcing would drop to $+5 \mathrm{~W} \mathrm{~m}^{-2}$. The decrease of the forcing can be explained by the decreasing temperature difference between the surface and the cooler dust layer; an observer from above could (thermally) not distinguish the two emitters.

The thermal infrared radiative forcing at the surface varies much less with surface temperature, because it is dominated by the temperature of the dust layer which was not varied in these calculations. The dust-layer emissions lead to a surface forcing in the range from +22 to $+26 \mathrm{~W} \mathrm{~m}^{-2}$.

\subsection{Net radiative forcing}

To get an idea of the overall radiative effect of the Saharan dust, the net forcing (solar plus thermal infrared) is shown in Fig. 14. For the thermal infrared component the surface temperature has been chosen as $40^{\circ} \mathrm{C}$ which is the average of the diurnal cycle on 19 May. Then the net radiative forcing has the same slope as the solar component, but is shifted to larger values between 0 and $24 \mathrm{~W} \mathrm{~m}^{-2}$. Most notably, the net radiative forcing at TOA has only positive values for the entire range of surface albedo encountered during this flight. However, the additional data point for zero surface albedo and the slope suggest that it would turn negative over darker surfaces than encountered, namely with a broad-band surface albedo lower than 0.1 .

The net radiative forcing at the surface takes values between -40 and $-22 \mathrm{~W} \mathrm{~m}^{-2}$. The dust layer always cools the surface because it absorbs and scatters radiation back upward. 


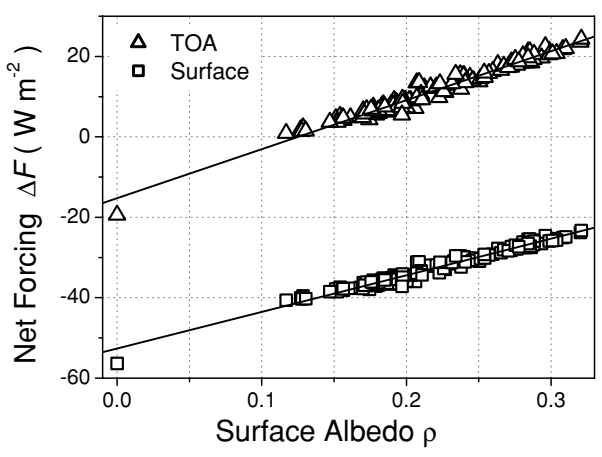

Fig. 14. Net (solar plus thermal infrared) radiative forcing of the SAMUM Saharan dust in dependence on the surface albedo for the case of 19 May 2006, at TOA and at the surface. For the thermal infrared component the surface temperature was set to the average value of $40^{\circ} \mathrm{C}$. Net radiative forcing at TOA is always positive for all surface-albedo values encountered during the SAMUM campaign, but would be negative for darker surfaces such as ocean.

\section{Conclusions}

During the SAMUM campaign, surface-albedo spectra of typical surface types in southeastern Morocco have been derived from airborne measurements of the spectral upwelling and downwelling irradiances by the SMART-Albedometer. Such spectra have not been available before neither for this region of the Sahara desert nor at this spectral resolution. Typically, surface-albedo values lie between 0.12 and 0.30 at the red end of the visible spectrum $(700 \mathrm{~nm})$. They are considerably lower (around 0.10$)$ at the blue end $(400 \mathrm{~nm})$, while typically a plateau is observed with almost constant values between 900 and $2200 \mathrm{~nm}$ wavelength. An exception is the dry lake Iriki near the Algerian border, where salt sediments yield surfacealbedo values of 0.4 at $700 \mathrm{~nm}$ and up to 0.5 at $1600 \mathrm{~nm}$. The surface-albedo data can be downloaded at http://www.staff.unimainz.de/jaekel/AGStrahlung/samum/dust_eng.html .

These measured data sets of the spectral surface albedo have been used as boundary conditions to quantify the impact of surface-albedo variations on the radiative forcing of Saharan dust. A detailed case study for 19 May 2006 has been performed using a comprehensive set of atmospheric model input parameters obtained from actual measurements in the SAMUM community. The spectral TOA radiative forcing shows a strong dependence on the aerosol single-scattering albedo and on the spectral surface albedo. The broad-band TOA radiative forcing of the Saharan mineral dust has been calculated along the flight track of this day (solar, thermal infrared and net radiative forcing). It clearly follows the temporal pattern of the underlying surface albedo. From correlating it to the surface albedo we concluded that the solar TOA radiative forcing of the dust (on this day) would increase by $12 \mathrm{~W} \mathrm{~m}^{-2}$ when the underlying broadband surface albedo increases by 0.1 . Taking also the thermal infrared radiative forcing for the given surface temperature into account, the net TOA radiative forcing of the Saharan dust is found to be positive (i.e. a warming effect) for all surface types in this case study, while the results predict that it would turn negative above darker surfaces. This suggests a cooling effect of desert dust when transported over the ocean. The brightest surface types in this case study lead to a net dust radiative forcing at TOA of $24 \mathrm{~W} \mathrm{~m}^{-2}$, with a thermal infrared component of $15 \mathrm{~W} \mathrm{~m}^{-2}$ under the assumption of a surface temperature at the average value of $40^{\circ} \mathrm{C}$. Assuming instead the maximum measured surface temperature of $56^{\circ} \mathrm{C}$, the thermal infrared component would increase to $22 \mathrm{~W} \mathrm{~m}^{-2}$ and the net TOA radiative forcing would rise accordingly to $31 \mathrm{~W} \mathrm{~m}^{-2}$.

We have found that the radiative forcing of Saharan dust is strongly influenced by both the spectral surface albedo and the dust single-scattering albedo $\omega_{0}$. The range of values for $\omega_{0}$ obtained in SAMUM with different methods underlines that a careful determination is indispensable for any study on the radiative forcing of Saharan dust. But even with accurate knowledge of the aerosol optical properties, also the spectral surface albedo has a strong impact on the dust radiative forcing and at TOA can be decisive whether it has a warming or cooling effect.

\section{Acknowledgments}

We gratefully appreciate the technical support by enviscope GmbH: Harald Franke, Dieter Schell, and Rolf Maser. Special thanks to the pilot, Giuseppe Distratis. We are grateful to the SAMUM organising team, in particular to Detlef Müller. Bernhard Mayer provided valuable help with the radiative transfer model LIBRADTRAN. We would also like to thank Dr. Torsten Diehl (Carl Zeiss MicroImaging $\mathrm{GmbH}$ ) for his helpful service and patience. The present study was supported by the German Research Foundation within the Research Group SAMUM. The helpful suggestions by two anonymous reviewers are appreciated. This work is part of a $\mathrm{PhD}$ thesis submitted at Johannes Gutenberg University Mainz (Germany).

\section{References}

d'Almeida, G. A., Koepke, P. and Shettle, E. P. 1991. Atmospheric Aerosols-Global Climatology and Radiative Characteristics, A. DEEPAK Publishing. Hampton, Virginia, USA.

Ansmann, A., Tesche, M., Knippertz, P., Bierwirth, E., Althausen, D. and co-authors. 2008. Vertical profiling of convective dust plumes in southern Morocco during SAMUM. Tellus 61B, doi:10.1111/j.16000889.2008.00384.x.

Aoki, Te., Mikami, M. and Liu, W. 2002. Spectral albedos of desert surfaces and size distributions of soil particles measured around Qira and Aksu in the Taklimakan Desert. J. Arid Land Stud. 11, 259-266.

Balkanski, Y., Schulz, M., Claquin, T. and Guibert, S. 2007. Reevaluation of mineral aerosol radiative forcings suggests a better agreement with satellite and AERONET data. Atmos. Chem. Phys. 7, 81-95.

Chandrasekhar, S. 1950. Radiative Transfer. Oxford University Press, London, U.K. 
Christopher, S. A. and Jones, T. 2007. Satellite-based assessment of cloud-free net radiative effect of dust aerosols over the Atlantic Ocean. Geophys. Res. Lett. 34, doi:10.1029/2006GL027783.

Claquin, T., Roelandt, C., Kohfeld, K. E., Harrison, S. P., Tegen, I. and co-authors. 2003. Radiative forcing of climate by ice-age atmospheric dust. Clim. Dyn. 20, 193-202.

Coddington, O., Schmidt, K. S., Pilewskie, P., Gore, W. J., Bergstrom, R. W. and co-authors. 2008. Aircraft measurements of spectral surface albedo and its consistency with ground-based and space-borne observations. J. Geophys. Res. 113, D17209, doi:10.1029/2008JD010089.

Costa, M. J., Sohn, B.-J., Levizzani, V. and Silva, A. M. 2006. Radiative forcing of Asian dust determined from the synergized GOME and GMS satellite data-a case study. J. Meteorol. Soc. Jpn. 84, 8595.

Deepshikha, S., Satheesh, S. K. and Srinivasan, J. 2006. Dust aerosols over India and adjacent continents retrieved using METEOSAT infrared radiance, part II: quantification of wind dependence and estimation of radiative forcing. Ann. Geophys. 24, 63-79.

Díaz, J. P., Expósito, F. J., Torres, C. J., Herrera, F., Prospero, J. M. and co-authors. 2001. Radiative properties of aerosols in Saharan dust outbreaks using ground-based and satellite data: Applications to radiative forcing. J. Geophys. Res. 106, 18 403-18 416.

Diner, D. J., Beckert, J. C., Reilly, T. H., Bruegge, C. J., Conel, J. E. and co-authors. 1998. Multi-angle Imaging SpectroRadiometer (MISR) Instrument description and experiment overview. IEEE Trans. Geosci. Remote Sens. 36, 1072-1087.

Dinter, T., von Hoyningen-Huene, W., Burrows, J. P., Kokhanovsky, A. A., Bierwirth, E. and co-authors. 2008. Retrieval of aerosol optical thickness for desert conditions using MERIS observations during the SAMUM campaign. Tellus 61B, doi:10.1111/j.16000889.2008.00391.x.

Feister, U. and Grewe, R. 1995. Spectral albedo measurements in the UV and visible region over different types of surfaces. Photochem. Photobiol. 62, 736-744.

Grenfell, T. C., Warren, S. G. and Mullen, P. C. 1994. Reflection of solar radiation by the Antarctic snow surface at ultraviolet, visible, and near-infrared wavelengths. J. Geophys. Res. 99, 18 669-18 684.

Hansen, J., Sato, M. and Ruedy, R. 1997. Radiative forcing and climate response. J. Geophys. Res. 102, 6831-6864.

Haywood, J., Francis, P. N., Glew, M. D. and Taylor, J. P. 2001. Optical properties and direct radiative effect of Saharan dust: a case study of two Saharan dust outbreaks using aircraft data. J. Geophys. Res. 106, $18417-18430$.

Haywood, J., Francis, P., Osborne, S., Glew, M., Loeb, N. and co-authors. 2003. Radiative properties and direct radiative effect of Saharan dust measured by the C-130 aircraft during SHADE: 1 . Solar Spectrum. $J$. Geophys. Res. 108, doi:10.1029/2002JD002687.

Heese, B., Freudenthaler, V., Seefeldner, M. and Wiegner, M. 2002. Lidar Remote Sensing in Atmospheric and Earth Sciences. In: (eds. L. R. Bissonnette, G. Roy and G. Vallee). Defence Research and Development, Canada-Valcartier, Val-Belair, Canada, 71-74.

Heintzenberg, J. 2008. The SAMUM-1 experiment over Southern Morocco: overview and introduction. Tellus 61B, doi:10.1111/j.16000889.2008.00403.x.

Helmert, J., Heinold, B., Tegen, I., Hellmuth, O. and Wendisch, M. 2007. On the direct and semidirect effects of Saharan dust over Europe: a modeling study. J. Geophys. Res. 112, doi:10.1029/2006JD007444.
Highwood, E. J., Haywood, J. M., Silverstone, M. D., Newman, S. M. and Taylor, J. P. 2003. Radiative properties and direct radiative effect of Saharan dust measured by the C-130 aircraft during SHADE: 2. Terrestrial spectrum. J. Geophys. Res. 108, doi:10.1029/2002JD002552. von Hoyningen-Huene, W., Dinter, T., Kokhanovsky, A. A., Burrows, J. P., Wendisch, M. and co-authors. 2008. Measurements of desert dust optical characteristic at Porte au Sahara during SAMUM. Tellus 61B, doi:10.1111/j.1600-0889.2008.00405.x.

Jacobson, M. Z. 2001. Global direct radiative forcing due to multicomponent anthropogenic and natural aerosols. J. Geophys. Res. 106, $1551-1568$.

Jäkel, E., Wendisch, M., Kniffka, A. and Trautmann, T. 2005. Airborne system for fast measurements of upwelling and downwelling spectral actinic flux densities. Appl. Opt. 44, 434-444.

Kahn, R. A., Gaitley, B. J., Martonchik, J. V., Diner, D. J. and Crean, K. A. 2005. Multiangle Imaging Spectroradiometer (MISR) global aerosol optical depth validation based on 2 years of coincident Aerosol Robotic Network (AERONET) observations. J. Geophys. Res. 110, doi:10.1029/2004JD004706.

Kahn, R. A., Garay, M. J., Nelson, D. L., Yau, K. K., Bull, M. A. and co-authors. 2007. Satellite-derived aerosol optical depth over dark water from MISR and MODIS: comparisons with AERONET and implications for climatological studies. J. Geophys. Res. 112, doi:10.1029/2006JD008175.

Kahn, R., Petzold, A., Wendisch, M., Bierwirth, E., Dinter, T. and coauthors. 2008. Desert dust aerosol air mass mapping in the western Sahara, using particle properties derived from space-based multi-angle imaging. Tellus 61B, doi:10.1111/j.1600-0889.2008.00398.x.

Knippertz, P., Deutscher, C., Kandler, K., Müller, T., Schulz, O. and coauthors. 2007. Dust mobilization due to density currents in the Atlas region: observations from the Saharan Mineral Dust Experiment 2006 field campaign. J. Geophys. Res. 112, doi:10.1029/2007JD008774.

Knippertz, P., Ansmann, A., Althausen, D., Müller, D., Tesche, M. and co-authors. 2008. Dust mobilization and transport in the Northern Sahara during SAMUM 2006-a meteorological overview. Tellus 61B, doi:10.1111/j.1600-0889.2008.00380.x.

Kokhanovsky, A. A., Breon, F.-M., Cacciari, A, Carboni, E., Diner, D. and co-authors. 2007. Aerosol remote sensing over land: a comparison of satellite retrievals using different algorithms and instruments. Atmos. Res. 85, 372-394.

Kylling, A., Persen, T., Mayer, B. and Svenøe, T. 2000. Determination of an effective spectral surface albedo from ground-based global and direct UV irradiance measurements. J. Geophys. Res. 105, 49494959.

Levelt, P. F., van den Oord, G. H. J., Dobber, M. R., Mälkki and coauthors. 2006. The ozone monitoring instrument. IEEE Trans. Geosci. Remote Sens. 44, 1093-1101.

Liu, X., Penner, J. E., Das, B., Bergmann, D., Rodriguez, J. M. and co-authors. 2007. Uncertainties in global aerosol simulations: assessment using three meteorological data sets. J. Geophys. Res. 112, doi:10.1029/2006JD008216.

Lyamani, H., Olmo, F. J., Alcántara, A. and Alados-Arboledas, L. 2006. Atmospheric aerosols during the 2003 heat wave in southeastern Spain II: microphysical columnar properties and radiative forcing. Atmos. Environ. 40, 6465-6476.

Martonchik, J. V., Kahn, R. A. and Diner, D. J. 2008. Retrieval of Aerosol Properties over Land Using MISR Observations. In: Satellite 
Aerosol Remote Sensing Over Land (eds A. A. Kokhanovsky and G. de Leeuw). Springer, Berlin, in press.

Matthews, S., Schwerdtfeger, P. and Hacker, J. M. 2002. Use of albedo modelling and aircraft measurements to examine the albedo of Nauru. Aust. Meteorol. Mag. 51, 229-236.

Mayer, B. and Kylling, A. 2005. Technical note: the libRadtran software package for radiative transfer calculations-description and examples of use. Atmos. Chem. Phys. 5, 1855-1877.

McComiskey, A., Ricchiazzi, P., Gautier, C. and Lubin, D. 2006. Assessment of a three dimensional model for atmospheric radiative transfer over heterogeneous land cover. Geophys. Res. Lett. 33, doi:10.1029/2005GL025356.

Meloni, D., di Sarra, A., Di Iorio, T. and Fiocco, G. 2004. Direct radiative forcing of Saharan dust in the Mediterranean from measurements at Lampedusa Island and MISR space-borne observations. J. Geophys. Res. 109, doi:10.1029/2003JD003960.

Michalsky, J., Min, Q., Barnard, J., Marchand, R. and Pilewskie, P. 2003. Simultaneous spectral albedo measurements near the Atmospheric Radiation Measurement Southern Great Plains (ARM SGP) central facility. J. Geophys. Res. 108, doi:10.1029/2002JD002906.

Miller, R. L. and Tegen, I. 1998. Climate response to soild dust aerosols. J. Clim. 11, 3247-3267.

Miller, R. L., Tegen, I. and Perlwitz, J. 2004. Surface radiative forcing by soil dust aerosols and the hydrological cycle. J. Geophys. Res. 109, doi:10.1029/2003JD004085.

Miller, R. L., Cakmur, R. V., Perlwitz, J., Geogdzhayev, I. V., Ginoux, P. and co-authors. 2006. Mineral dust aerosols in the NASA Goddard Institute for Space Sciences ModelE atmospheric general circulation model. J. Geophys. Res. 111, doi:10.1029/2005JD005796.

Myhre, G. and Stordal, F. 2001. Global sensitivity experiments of the radiative forcing due to mineral aerosols. J. Geophys. Res. 106, $18193-$ 18204.

Myhre, G., Grini, A., Haywood, J. M., Stordal, F., Chatenet, B. and coauthors. 2003. Modeling the radiative impact of mineral dust during the Saharan Dust Experiment (SHADE) campaign. J. Geophys. Res. 108, doi: $10.1029 / 2002 J D 002566$.

Nair, U. S., Ray, D. K., Wang, J., Christopher, S. A., Lyons, T. J. and co-authors. 2007. Observational estimates of radiative forcing due to land use change in southwest Australia. J. Geophys. Res. 112, doi:10.1029/2006JD007505.

Otto, S., de Reus, M., Trautmann, T., Thomas, A., Wendisch, M. and co-authors. 2007. Atmospheric radiative effects of an in situ measured Saharan dust plume and the role of large particles. Atmos. Chem. Phys. 7, 4887-4903.

Otto, S., Bierwirth, E., Weinzierl, B., Kandler, K., Esselborn, M. and coauthors. 2008. Solar radiative effects of a Saharan dust plume observed during SAMUM assuming spheroidal model particles. Tellus 61B, doi:10.1111/j.1600-0889.2008.00389.x.

Perlwitz, J., Tegen, I. and Miller, R. L. 2001. Interactive soil dust aerosol model in the GISS GCM. 1. Sensitivity of the soil dust cycle to radiative properties of soil dust aerosols. J. Geophys. Res. 106, 18 16718192.

Pilewskie, P., Pommier, J., Bergstrom, R., Gore, W., Howard, S. and co-authors. 2003. Solar spectral radiative forcing during the Southern African regional science initiative. J. Geophys. Res. 108, doi:10.1029/2002JD002411.
Ricchiazzi, P. and Gautier, C. 1998. Investigation of the effect of surface heterogeneity and topography on the radiation environment of Palmer Station, Antarctica, with a hybrid 3-D radiative transfer model. $J$. Geophys. Res. 103, 6161-6176.

Ricchiazzi, P., Yang, S., Gautier, C. and Sowle, D. 1998. SBDART: a research and teaching software tool for plane-parallel radiative transfer in the Earth's atmosphere. Bull. Am. Meteorol. Soc. 79, 2101-2114.

Rockwood, A. A. and Cox, S. K. 1978. Satellite inferred surface albedo over Northwestern Africa. J. Atmos. Sci. 35, 513-522.

Rutan, D. A., Rose, F. G., Madigan, J. and Charlock, T. P. 2003. Surface albedo at the atmospheric radiation measurement Southern Great Plains site from helicopter observations. In: Thirteenth Atmospheric Radiation Measurement (ARM) Program Science Team Meeting (ed. D. Carrothers). US Department of Energy, Richland, WA, 1-9.

Schaaf, C. B., Gao, F., Strahler, A. H., Lucht, W., Li, X. and co-authors. 2002. First operational BRDF, albedo nadir reflectance products from MODIS. Remote Sens. Environ. 83, 135-148.

Schladitz, A., Müller, T., Massling, A., Kaaden, N., Kandler, K. and co-authors. 2008. In situ measurements of optical properties at Tinfou (Morocco) during the Saharan Mineral Dust Experiment SAMUM 2006. Tellus 61B, doi:10.1111/j.1600-0889.2008.00397.x.

Shell, K. and Somerville, R. C. J. 2007a. Direct radiative effect of mineral dust and volcanic aerosols in a simple aerosol climate model. J. Geophys. Res. 112, doi:10.1029/2006JD007197.

Shell, K. and Somerville, R. C. J. 2007b. Sensitivity of climate forcing and response to dust optical properties in an idealized model. $J$. Geophys. Res. 112, doi:10.1029/2006JD007198.

Sokolik, I. N. and Toon, O. B. 1996. Direct radiative forcing by anthropogenic airborne mineral aerosols. Nature 381, 681-683.

Song, J. and Gao, W. 1999. An improved method to derive surface albedo from narrowband AVHRR satellite data: narrowband to broadband conversion. J. Appl. Meteorol. 38, 239-249.

Stamnes, K., Tsay, S.-C., Wiscombe, W. and Jayaweera, K. 1988. Numerically stable algorithm for discrete-ordinate-method radiative transfer in multiple scattering and emitting layered media. Appl. Opt. 27, 2502-2509.

Stone, R. S., Anderson, G. P., Andrews, E., Dutton, E. G., Shettle, E. P. and co-authors. 2007. Incursions and radiative impact of Asian dust in northern Alaska. Geophys. Res. Lett. 34, doi:10.1029/2007GL029878.

Tegen, I. and Lacis, A. A. 1996. Modeling of particle size distribution and its influence on the radiative properties of mineral dust aerosol. J. Geophys. Res. 101, 19237-19244.

Tegen, I., Lacis, A. A. and Fung, I. 1996. The influence on climate forcing of mineral aerosols from disturbed soils. Nature 380, 419-422.

Tesche, M., Ansmann, A., Müller, D., Althausen, D., Mattis, I. and coauthors. 2008. Vertical profiling of Saharan dust with Raman lidars and airborne HSRL in southern Morocco during SAMUM. Tellus 61B, doi:10.1111/j.1600-0889.2008.00390.x.

Thomas, G. E., Poulsen, C. A., Curier, R. L., de Leeuw, G., Marsh, S. H. and co-authorss. 2007. Comparison of AATSR and SEVIRI aerosol retrievals over the Northern Adriatic. Quart. J. R. Meteorol. Soc. 133(S1), 85-95.

Trishchenko, A. P., Luo, Y., Khlopenkov, K. and Li, Z. 2004. Dynamics of the surface albedo over the ARM SGP area during Spring 2003 aerosol IOP. In: Proceedings of Fourteenth ARM Science Team Meeting. US Department of Energy, Washington, D.C. 
Wang, H., Shi, G., Li, S., Li, W., Wang, B. and co-authors. 2006. The impacts of optical properties on radiative forcing due to dust aerosol. Adv. Atmos. Sci. 23, 431-441.

Webb, A. R., Stromberg, I. M., Li, H. and Bartlett, L. M. 2000. Airborne spectral measurements of surface reflectivity at ultraviolet and visible wavelengths. J. Geophys. Res. 105, 4945-4948.

Webb, A. R., Kylling, A., Wendisch, M. and Jäkel, E. 2004. Airborne measurements of ground and cloud spectral albedos under low aerosol loads. J. Geophys. Res. 109, doi:10.1029/2004JD004768.

Wendisch, M. and Mayer, B. 2003. Vertical distribution of spectral solar irradiance in the cloudless sky: a case study. Geophys. Res. Lett. 30, doi:10.1029/2002GL016529.

Wendisch, M., Müller, D., Schell, D. and Heintzenberg, J. 2001. An airborne spectral albedometer with active horizontal stabilization. $J$. Atmos. Oceanic Technol. 18, 1856-1866.

Wendisch, M., Pilewskie, P., Jäkel, E., Schmidt, S., Pommier, J. and co-authors. 2004. Airborne measurements of areal spectral surface albedo over different sea and land surfaces. J. Geophys. Res. 109, D08203, doi:10.1029/2003JD004392.
Wiegner, M., Gasteiger, J., Kandler, K., Weinzierl, B., Rasp, K. and co-authors. 2008. Numerical simulations of optical properties of Saharan dust aerosols with emphasis on lidar applications. Tellus 61B, doi:10.1111/j.1600-0889.2008.00381.x.

Woodward, S. 2001. Modeling the atmospheric life cycle and radiative impact of mineral dust in the Hadley Centre climate model. $J$. Geophys. Res. 106, 18 155-18 166.

Wuttke, S., Seckmeyer, G. and König-Langlo, G. 2006. Measurements of spectral snow albedo at Neumayer, Antarctica. Ann. Geophys. 24, 7-21.

Yoshioka, M., Mahowald, N., Conley, A. J., Collins, W. D., Fillmore, D. W. and co-authors. 2007. Impact of desert dust radiative forcing on Sahel precipitation: relative importance of dust compared to sea surface temperature variations, vegetation changes, and greenhouse gas warming. J. Clim. 20, 14451467.

Zhu, A., Ramanathan, V., Li, F. and Kim, D. 2007. Dust plumes over the Pacific, Indian, and Atlantic oceans: climatology and radiative impact. J. Geophys. Res. 112, doi:10.1029/2007JD008427. 